\title{
Revisão Sistemática de Trabalhos sobre Concepções de Natureza da Ciência no Ensino de Ciências
}

\section{A Systematic Review of Studies About Conceptions on the Nature of Science in Science Education}

\author{
Nathália Helena Azevedo ${ }^{\circledR}$ Brasil \\ Daniela Lopes Scarpa ${ }^{\circledR}$ Brasil
}

A natureza da ciência $(\mathrm{NdC})$ tem sido apontada como um componente importante do ensino de ciências, pois o conhecimento sobre a ciência pode contribuir para a tomada de decisões do cidadão contemporâneo. Há poucos trabalhos de revisão com caráter quantitativo no campo da educação em ciências. Dada a importância do tema e considerando a necessidade de organizar e compreender o conhecimento produzido pelas pesquisas sobre concepções de $\mathrm{NdC}$, realizamos uma revisão sistemática, segundo os princípios do PRISMA, a fim de quantificar e iniciar uma reflexão sobre (i) as tendências de publicação de trabalhos sobre concepções de $\mathrm{NdC}$, (ii) as principais características desses trabalhos, (iii) os aspectos de $\mathrm{NdC}$ frequentemente elencados como importantes para o ensino e (iv) as principais estratégias usadas para acessar as concepções de NdC. Analisamos 396 artigos publicados até fevereiro de 2015, nos periódicos de Ensino e Educação da lista WebQualis 2013. Nossa revisão sistemática representou um esforço inicial para expor um panorama geral da área e permitiu identificar tendências e lacunas de pesquisa. Esforços de investigação são necessários para o levantamento de concepções de $\mathrm{NdC}$ no contexto brasileiro e associados ao ensino de disciplinas específicas. Encontramos 25 aspectos de $\mathrm{NdC}$ relatados como importantes para o ensino, abordamos parte do debate acerca dos consensos e das listas de aspectos de $\mathrm{NdC}$ e trouxemos características gerais dos principais questionários usados para o levantamento de concepções de NdC.

Palavras-chave: concepções de ciência; instrumentos de pesquisa; listas de aspectos de $\mathrm{NdC}$; revisão sistemática; tendências de pesquisa, visão consensual.

The nature of science (NOS) has been highlighted as an important component of science education, since scientific knowledge can contribute to decision-making by contemporary citizens. There are few quantitative review studies in the field of science education. Given the importance of the topic, and the need to organize and understand the knowledge produced by research on conceptions of NOS, we carried out a systematic review based on the principles of PRISMA, in order to quantify and initiate reflection on (i) the publication trends of articles on NOS conceptions (ii) the main characteristics of 
these articles, (iii) the NOS aspects frequently cited as important for teaching, and (iv) the main strategies used to access NOS conceptions. We analyzed 396 articles published up to February 2015 in Teaching and Education journals listed on WebQualis 2013. Our systematic review represented an initial effort to present an overview of the area, and enabled us to identify research trends and gaps. Investigational efforts are needed to investigate NOS conceptions in the Brazilian context that are associated with the teaching of specific disciplines. We found twenty-five NOS aspects reported to be important for teaching, addressed part of the debate on consensus and the lists of NOS aspects, and presented general characteristics of the main questionnaires used to investigate NOS conceptions.

Keywords: conceptions of science; consensus view; lists of NoS aspects; NOS lists; NOS views; research methods; research trends; systematic review; survey instruments.

\section{Introdução}

Estudantes em diferentes níveis educacionais podem apresentar concepções de ciência e sobre o trabalho do cientista que são distantes do real. A distância entre a concepção dos alunos e o real possivelmente ocorre porque há uma imagem enviesada e descontextualizada associada à ciência e ao trabalho dos cientistas que é constantemente reforçada fora da sala de aula (Hodson, 1998). Identificar as concepções dos alunos sobre ciência pode auxiliar o professor a planejar melhor suas aulas e a identificar quão distorcida é a imagem que os alunos têm da ciência. Na tentativa de dar sentido ao que se aprende, os estudantes pensam nos conceitos científicos a partir de suas concepções. Há, então, um potencial descompasso entre as concepções do professor, as dos alunos e até mesmo as do material didático, o que pode tornar desafiadora a proposta de um aprendizado crítico, pois as crenças epistemológicas dos estudantes podem influenciar seu processo de aprendizagem (Lidar, Lundqvist, \& Ostman, 2006).

Apesar do papel que as experiências fora do ambiente escolar podem desempenhar nas visões de ciência de um indivíduo, a sala de aula pode reforçar concepções inadequadas de ciência (Gil-Pérez, Fernández, Carrascosa, Cachapuz, \& Praia, 2001), sobretudo quando o processo de ensino e aprendizagem de ciências se apoia na mera transmissão de conceitos, na qual os estudantes devem apenas repetir e decorar definições, não tendo oportunidades de conhecer, compreender e refletir sobre o processo de produção do conhecimento científico. A literatura tem indicado a presença de concepções inadequadas sobre a ciência nos diversos níveis de formação (p. ex., Abd-El-Khalick \& Lederman, 2000; Ajaja, 2012; Hacieminoglu, Yilmaz-Tuzun, \& Ertepinar, 2012; Moss, Abrams \& Robb, 2001; Waters-Adams \& Nias, 2003), enunciando a necessidade de entender os fatores que levam a tais concepções, de refletir sobre o conhecimento que vem sendo construído na área e de repensar estratégias que sejam eficazes para superar concepções pouco informadas acerca da ciência.

A presença de concepções inadequadas sobre a ciência nos diversos níveis de 
ensino é preocupante, dado que temas científicos estão cada vez mais presentes no cotidiano, exigindo decisões diversas do cidadão, como para avaliar criticamente se seguirá determinado tratamento de saúde, se adotará certa dieta, ou qual equipamento eletrônico comprará. Tais decisões precisam ser dotadas de sentido e, para isso, os estudantes precisam saber, por exemplo, que os cientistas também erram e que há diversas fontes de vieses no trabalho científico. Em muitas das situações corriqueiras, é necessário que os alunos saibam avaliar a qualidade de dados e argumentos para que possam tomar suas decisões (Fourez, 1997; Hodson, 2001), pois na ciência, muito mais importante do que as afirmações que são produzidas, é a forma como os cientistas geram dados e validam o conhecimento (Lemke, 2001). Assim, o processo de ensino e aprendizagem de ciências precisa contemplar as dimensões do "aprender ciência" (conhecimentos conceituais e teóricos), "aprender a fazer ciência" (engajamento na resolução de problemas), "aprender sobre ciências" (características do processo de construção de conhecimento e relações entre ciência, tecnologia, sociedade e ambiente) e "aprender a lidar com temas sociocientíficos" (confrontar diferentes aspectos para a tomada de decisão em temas sociocientíficos) (Hodson, 2014, p. 2537). O aprendizado conceitual tem sido fortemente priorizado nas aulas de ciências, nas quais o modelo atual de ensino e aprendizagem ainda é focado em um padrão de instrução baseado na memorização de informações (Carvalho 2006; Figueirêdo \& Justi, 2011; Freitas, 2008). De modo contrário, Hodson (2014) defende que todas as dimensões envolvidas nos objetivos do ensino de ciências estejam no mesmo patamar de importância.

Diante desse cenário, os pesquisadores em ensino de ciências têm investigado concepções de estudantes na tentativa de compreendê-las e de construir um corpus teórico-prático capaz de contribuir para um aprendizado que contemple uma abordagem contextual (Allchin, 2011; Azevedo \& Scarpa, 2017), explícita e reflexiva acerca da natureza da ciência (Duschl \& Grandy, 2013; Khishfe, 2014; Lederman, 2007; Matthews, 1992). Assim, consideramos que o aprendizado de ciências precisa possibilitar a compreensão sobre como o conhecimento científico é produzido, validado e comunicado, considerando as particularidades epistemológicas da ciência de forma explícita.

O termo natureza da ciência $(\mathrm{NdC})$ é usado por alguns autores para se referir à natureza do conhecimento científico ou à epistemologia da ciência (p. ex., AbdEl-Khalick \& Lederman, 2000; Lederman, 1992). Outros diferenciam a natureza do conhecimento científico da natureza da investigação científica (p. ex., Schwartz et al., 2008), restringindo os processos pelos quais o conhecimento é produzido e justificado nesta última categoria. Apesar das diferentes denominações, há relativo consenso de que os aspectos fundamentais sobre a $\mathrm{NdC}$ incluem: as características da investigação científica (suas etapas de investigação e métodos), o papel do conhecimento gerado, os paradigmas que orientam os trabalhos dos cientistas, como os cientistas trabalham como um grupo social e como a ciência pode ser afetada pelo contexto social em que está inserida (Clough \& Olson, 2008; Osborne, Collins, Ratcliffe, Millar, \& Duschl, 2003; 
Wong \& Hodson, 2009).

Na literatura, há muitas justificativas para a inclusão da reflexão sobre o processo de produção do conhecimento científico em sala de aula (p. ex., Bell \& Lederman, 2003; Clough \& Olson, 2008; Hodson, 2001; Osborne, Collins, Ratcliffe, Millar, \& Duschl, 2003; Taber, 2010) e a NdC tem sido considerada um componente importante nos currículos de educação em ciências em nível global (Abd-El-Khalick et al., 2004; Khishfe \& AbdEl-Khalick, 2002; Ogunniyi, 2005). Por esses motivos, investigar as concepções de NdC tem se tornado uma área relevante associada às pesquisas sobre o ensino de ciências (Lederman, 1992) nos diversos níveis de ensino. Algumas revisões tradicionais (p. ex., Abd-El-Khalick \& Lederman 2000; Lederman, 2007) já se propuseram a sintetizar alguns aspectos dessa área de pesquisa, porém, levando em consideração um número restrito de trabalhos publicados em língua inglesa.

Assim, dada a importância do tema, considerando que há poucos trabalhos de revisão no campo da educação em ciências (Tsai \& Wen, 2005) e, ainda, considerando a necessidade de organizar e compreender o conhecimento produzido pelas pesquisas sobre concepções de $\mathrm{NdC}$, nosso objetivo aqui é fazer uma revisão sistemática que inclua não apenas periódicos de língua inglesa, mas sobretudo os latino-americanos, além de trazer uma visão um pouco mais quantitativa para o que tem sido produzido na área de $\mathrm{NdC}$, a fim de refletir sobre as informações presentes nesses trabalhos.

Esta revisão sistemática fez parte da primeira etapa de um trabalho maior, que visou construir um instrumento contextualizado para o levantamento de concepções de NdC de graduandos brasileiros de Biologia (Azevedo \& Scarpa, 2017). Uma sondagem inicial indicou a necessidade de olhar de forma organizada e cuidadosa para a grande quantidade de trabalhos voltados para o levantamento de concepções de NdC. Tal necessidade nos levou a procurar uma metodologia capaz de mapear, de forma estratégica e sistematizada, os trabalhos publicados na área, a fim de encontrar possíveis respostas que pudessem nortear a elaboração de um instrumento de pesquisa relevante e significativo para as pesquisas sobre a $\mathrm{NdC}$ no ensino de ciências e que fosse efetivo para um levantamento de concepções de $\mathrm{NdC}$. Assim, a presente revisão sistemática visa quantificar e apresentar análises exploratórias sobre o contexto atual das pesquisas sobre concepções de $\mathrm{NdC}$, a fim de lançar luz sobre em que contextos esforços de pesquisa ainda podem ser necessários. Para tanto, a revisão está orientada pelas seguintes questões:

(i) Quais as tendências de publicação dos trabalhos sobre concepções de NdC?

Pretendemos investigar se há um crescimento nesse tipo de pesquisa e se há um perfil de periódicos que publica esses trabalhos com mais frequência.

(ii) Quais as características desses trabalhos?

Interessa-nos mapear (a) quais os recortes de pesquisa mais comuns, (b) se há disciplinas ou áreas do conhecimento que estão mais interessadas em compreender as concepções de um público, (c) qual o foco de estudo nos trabalhos de levantamento das concepções 
de $\mathrm{NdC}$ e (d) em que países as concepções de NdC são pesquisadas com mais frequência.

(iii) Quais aspectos de $\mathrm{NdC}$ costumam ser elencados como importantes para o ensino nesses trabalhos?

Sabendo que há uma diversidade de aspectos frequentemente relatados, por diversos autores, como relevantes para o ensino, pretendemos identificar quais são esses aspectos.

(iv) Quais as principais estratégias usadas para acessar as concepções de $\mathrm{NdC}$ ?

Interessa-nos investigar se são usados questionários, entrevistas ou outras formas de acessar concepções de NdC. Havendo instrumentos mais recorrentes, pretendemos identificar quais suas principais características, quanto à forma e ao conteúdo.

\section{Metodologia}

Para o planejamento da revisão, partimos dos princípios formulados pelo PRISMA (Preferred Reporting Items for Systematic reviews and Meta-Analyses), devido à clareza de suas instruções e à validade reconhecida em diferentes áreas de pesquisa. Os princípios estabelecidos pelo PRISMA são resultantes da construção coletiva de um grupo de pesquisadores interessados em organizar o conhecimento e sintetizar informações relevantes. O PRISMA adota como revisão sistemática aquela que revisa uma questão relevante para determinada área, com o uso de "métodos sistemáticos e explícitos para identificar, selecionar e avaliar criticamente pesquisas relevantes e para coletar e analisar dados dos estudos incluídos na revisão" (Moher, Liberati, Tetzlaff, \& Altman, 2009, p. 1).

Embora os princípios formulados pelo PRISMA tenham como foco trabalhos de revisão sistemática de áreas de pesquisa como a Saúde, a transparência e a replicabilidade de suas etapas nos parecem apropriadas para revisões acuradas também para a área de Humanidades. As revisões da área de Ensino, em geral, seguem um modelo em que os autores costumam partir de uma amostragem não sistematizada e com critérios não explicitados. Esse tipo de revisão pode ser definida como revisão tradicional ou narrativa e caracteriza-se por descrever e avaliar trabalhos anteriores, mas sem descrever métodos específicos pelos quais os estudos revisados foram identificados, selecionados e avaliados (Knopf, 2006). Assim, embora tal modelo de revisão possibilite uma visão geral e discussões relevantes e críticas sobre trabalhos anteriores, a seleção dos trabalhos para uma revisão dessa natureza permanece desconhecida para os leitores e pode carregar uma série de vieses quanto à inclusão ou não de determinados trabalhos da literatura.

Protocolos bem estabelecidos como o do PRISMA são relevantes, pois a qualidade dos relatos presentes em trabalhos de revisão tradicional pode variar, limitando a interpretação dos leitores quanto às reais lacunas de uma dada área. Os princípios do PRISMA permitem construir um panorama abrangente por meio de processos 
explícitos e pressupostos metodológicos replicáveis por outros pesquisadores. Assim, tais princípios fornecem a possibilidade de descrever um panorama amplo das pesquisas sobre $\mathrm{NdC}$ no ensino de ciências.

Diante de tal cenário, procuramos seguir à risca as recomendações do PRISMA, incorporando na nossa revisão as etapas de: (i) identificação, triagem e seleção das publicações relevantes, (ii) avaliação crítica dos artigos selecionados e (iii) apresentação dos resultados de forma clara (Moher et al., 2009). Além de sumarizar as pesquisas de interesse em determinado assunto, a revisão sistemática tem o objetivo de ser clara e precisa no seu protocolo (ou método) de revisão. Essas etapas são exploradas em detalhes nas seções seguintes, cujo conteúdo advém das recomendações enunciadas pelo PRISMA.

\section{Estratégia de busca e seleção das fontes apropriadas de informações}

Uma busca exploratória inicial foi feita nas bases de dados da Web of Science e do Scopus. Nessa fase, procuramos identificar os termos de busca que seriam mais inclusivos para os objetivos do nosso estudo e avaliar se os periódicos indexados nessas bases são representativos para as áreas de Educação e Ensino considerando o contexto de pesquisa brasileiro. A escolha dessas bases facilitaria a organização do nosso banco de dados de artigos e a quantificação de algumas informações, sobretudo pela possibilidade de exportação dos relatórios de busca de termos e citações. Entretanto, os periódicos brasileiros, assim como os de outros países em desenvolvimento, têm dificuldades de integrar sua produção científica nas bases internacionais de informação científica (Packer, 2011). De todas as áreas do conhecimento, a Web of Science soma 11.500 periódicos indexados enquanto o Scopus, 29.385. Desses periódicos, apenas 114 e 309, respectivamente, são brasileiros (Rodrigues, Quartiero, \& Neubert, 2015). Consideramos ainda que há um grande número de artigos relevantes das áreas de Ensino e Educação que não são publicados em inglês (língua dominante nessas bases de dados). Dessa forma, devido à quantidade de publicações em Português e Espanhol da nossa área de interesse, poderíamos não identificar artigos relevantes publicados nos periódicos latino-americanos não indexados, caso a busca fosse feita de outra maneira.

Diante desse cenário, optamos por sistematizar as buscas partindo de uma lista abrangente de periódicos, o que nos permitiria estabelecer uma busca ampla e certa confiabilidade na generalização dos dados. A lista do Programa Qualis Periódicos da Coordenação de Aperfeiçoamento de Pessoal de Ensino Superior (CAPES), conhecida como WebQualis, pareceu-nos uma boa opção. A WebQualis deriva do indicador da Web of Science (Packer, 2011) e resulta de um conjunto de procedimentos adotados pela CAPES para categorizar a qualidade da produção intelectual de programas de pósgraduação. Esse procedimento se dá via análise da qualidade dos periódicos científicos nos quais houve publicação dos programas avaliados (CAPES, 2015). Os periódicos são estratificados em sete categorias que indicam sua qualidade, sendo A1 a mais elevada, seguidas dos estratos A2, B1, B2, B3, B4, B5 e C. A avaliação é realizada por diferentes 
áreas, que podem delimitar independentemente os seus critérios de avaliação e pontos de corte para inclusão de um periódico em determinado estrato. Um mesmo periódico pode ser avaliado por diferentes áreas e, portanto, ser classificado em estratos diferentes em cada uma delas. Os critérios adotados em cada área para essa estratificação são estabelecidos por um grupo de especialistas dessas áreas. A lista dos periódicos é atualizada a cada três anos e publicada junto com os critérios de inclusão dos periódicos por estrato, conforme a área (CAPES, 2015).

Dentre os fatores para a decisão de utilizar a lista WebQualis, ponderamos que: (i) partir de uma lista poderia facilitar uma busca fora de indexadores, dado que facilitaria a organização de um banco de dados próprio para a nossa revisão; (ii) os critérios de inclusão e qualidade dos periódicos já passaram por uma avaliação ampla de pares e estão publicados com acesso fácil; (iii) a lista inclui um maior número de periódicos em comparação com bases indexadas, podendo permitir buscas mais inclusivas e (iv) por incluir um maior número de periódicos latino-americanos, poderíamos fazer uma avaliação mais ampla e contextualizada dos artigos.

\section{Critérios de seleção e exclusão}

Para a seleção dos periódicos, consideramos aqueles pertencentes desde o estrato A1 até o B3, das áreas de Ensino e Educação, da lista WebQualis 2013. Porém, dessa lista, excluímos todos os periódicos cujo foco em Educação ou em Ensino não estavam explicitados em seus respectivos sites. Tal medida deriva do fato de que muitos periódicos têm seções ou números especiais destinados ao Ensino e à Educação, o que resulta em eles serem integrados nessas áreas na lista do WebQualis. Entretanto, esses periódicos não publicam trabalhos com esse foco com frequência e não possuem um corpo editorial nessas áreas, sendo pouco expressivos para os pesquisadores interessados em trabalhos sobre NdC. Permaneceram na lista os periódicos de ensino de ciências em geral, que envolvem ou não temas de tecnologia, matemática e sociedade; todos os periódicos de Educação, inclusive aqueles voltados para o ensino superior. Foram excluídos os periódicos sobre ensino de áreas muito específicas como Estatística, Geologia, Astronomia e disciplinas associadas à área da Saúde, por exemplo. A listagem dos periódicos que consultamos pode ser visualizada, na íntegra, no Apêndice 1.

Para a seleção dos artigos, identificamos as principais expressões utilizadas nos títulos e palavras-chave e organizamos uma lista de busca (Figura 1). Para a seleção dos artigos sobre $\mathrm{NdC}$, acessamos diretamente o site de cada um dos periódicos selecionados e em cada site realizamos a busca por artigos seguindo a lista de termos. Consideramos todos os artigos publicados até fevereiro de 2015. Dessa forma, não estabelecemos um ano inicial de publicação para inclusão do artigo no nosso banco de dados, pois pretendíamos incluir o máximo possível de trabalhos. Não computamos as publicações caracterizadas como cartas, editoriais, resenhas e comentários.

Assim, nossa revisão sistemática contemplou quatro grandes etapas (Figura 2): (i) identificação (seleção dos periódicos e levantamento preliminar dos artigos), (ii) 
triagem (durante a qual, devido à leitura mais detalhada dos artigos, excluímos aqueles cujas concepções de $\mathrm{NdC}$ não eram o foco principal), (iii) seleção (análise detalhada dos artigos) e (iv) inclusão (fechando o banco de dados). Destacamos que, após a etapa de seleção inicial dos artigos, foram excluídos os artigos que abordavam outras concepções (por exemplo: concepções sobre a teoria da evolução ou concepções sobre o conceito de força), as duplicatas de artigos publicados em mais de um periódico (em diferentes idiomas ou com variações de redação e estrutura) e aqueles cujo texto integral não estava disponível.

\begin{tabular}{|l|l|}
\hline Idioma & Expressões de busca \\
\hline Português & $\begin{array}{l}\text { natureza da ciência, concepção/concepções de ciência, imagem/imagens da ciência, } \\
\text { visão de ciência }\end{array}$ \\
\hline Inglês & $\begin{array}{l}\text { nature of science (NOS), views of nature of science (VNOS), images of science, beliefs } \\
\text { about nature of science, scientist work }\end{array}$ \\
\hline Espanhol & naturaleza de la ciencia, concepciones epistemológicas, percepción de la ciencia \\
\hline
\end{tabular}

Figura 1. Listas de expressões usadas para as buscas de artigos diretamente no site dos periódicos selecionados

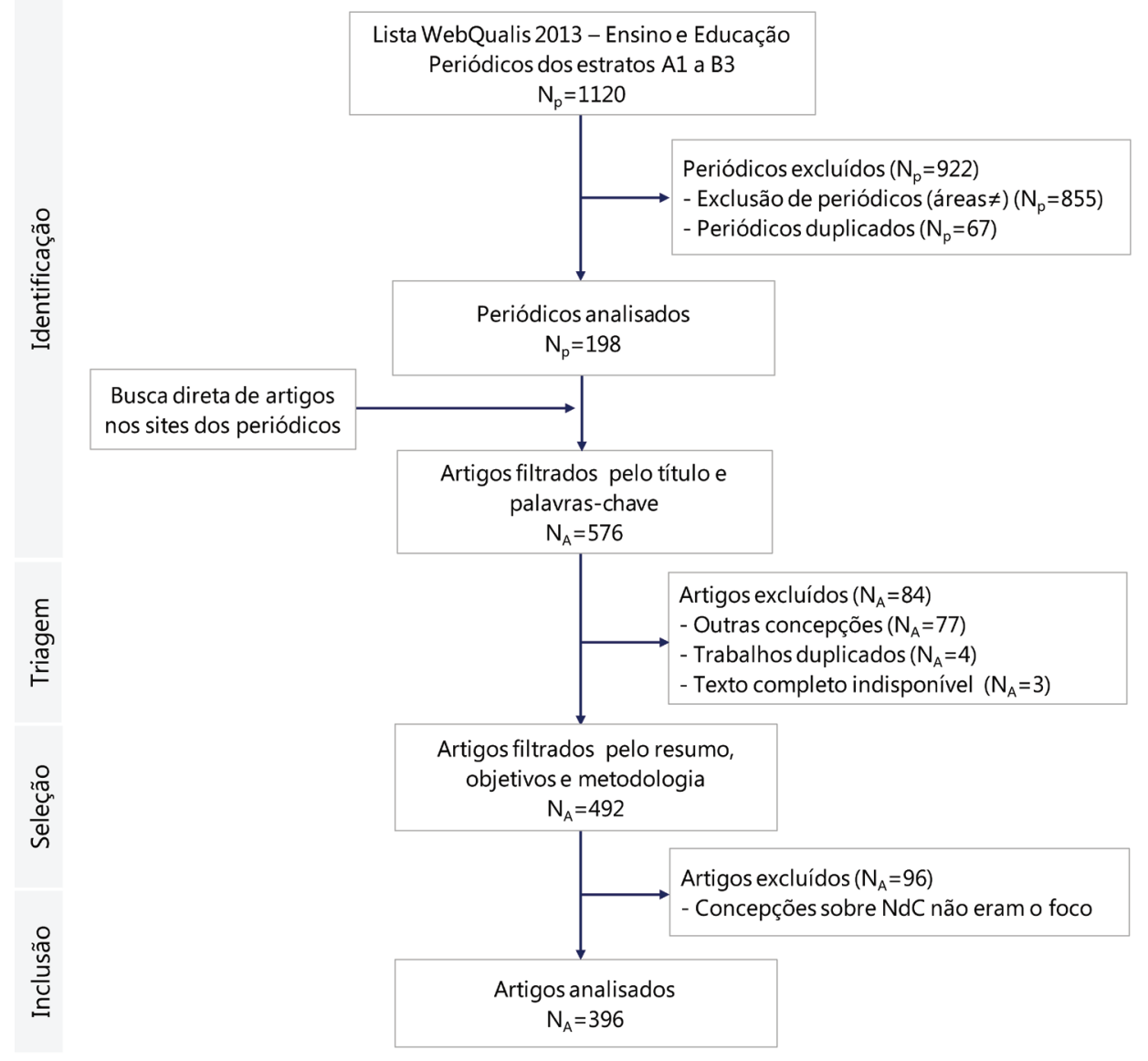

Figura 2. Diagrama, segundo os critérios do PRISMA, representando a amostragem dos artigos em cada estágio da nossa revisão sistemática. Legenda: $\mathrm{N}_{\mathrm{p}}$ corresponde ao número de periódicos e $\mathrm{N}_{\mathrm{A}}$, ao número de artigos. 


\section{Extração das informações dos artigos e análises}

Criamos categorias a priori para classificar os artigos conforme os objetivos que adotamos para esta revisão (Figura 3). Entretanto, as categorias foram constantemente refinadas ao longo da amostragem e das leituras. Uma vez que a revisão sistemática é um processo iterativo (Moher et al., 2009), no qual a classificação dos trabalhos se dá de forma dinâmica, não sendo possível delimitar todas as etapas da metodologia a priori. Sempre que necessário, os artigos já categorizados foram reavaliados conforme as novas categorias de classificação. Todas as etapas da revisão foram tabuladas, bem como as classificações que adotamos. Com a finalidade de permitir a recuperação de informações e minimizar as chances de erros, nenhum artigo foi excluído do nosso banco de dados.

\begin{tabular}{|c|c|c|}
\hline Pergunta da revisão & Descrição da categoria & Divisões das categorias \\
\hline $\begin{array}{l}\text { (i) Quais as tendências } \\
\text { de publicação dos } \\
\text { trabalhos sobre } \\
\text { concepções de NdC? }\end{array}$ & $\begin{array}{l}\text { Qualis do periódico. } \\
\text { Ano de publicação do } \\
\text { artigo. }\end{array}$ & \\
\hline \multirow{4}{*}{$\begin{array}{l}\text { (ii) Quais as } \\
\text { características desses } \\
\text { trabalhos? }\end{array}$} & $\begin{array}{l}\text { Disciplinas ou área } \\
\text { do conhecimento } \\
\text { associadas às } \\
\text { concepções de NdC. }\end{array}$ & $\begin{array}{l}\text { Separamos os artigos conforme a disciplina } \\
\text { associada ao periódico ou ao tema do artigo. } \\
\text { As categorias são: Biologia, Física, Química e } \\
\text { Ciências em geral. }\end{array}$ \\
\hline & $\begin{array}{l}\text { Tipo de artigo, } \\
\text { conforme o recorte } \\
\text { definido pelos autores. }\end{array}$ & $\begin{array}{l}\text { Separamos os artigos conforme os objetivos } \\
\text { relatados pelos autores: artigos de levantamento } \\
\text { de concepções de NdC de um grupo, } \\
\text { posicionamento teórico dos autores, revisão } \\
\text { tradicional da literatura, criação de um novo } \\
\text { instrumento de avaliação de concepções de NdC } \\
\text { e outros tipos de revisões. }\end{array}$ \\
\hline & $\begin{array}{l}\text { Foco de estudo nos } \\
\text { artigos de levantamento } \\
\text { das concepções de } \\
\text { NdC. }\end{array}$ & $\begin{array}{l}\text { Criamos } 13 \text { subcategorias, conforme o foco } \\
\text { em um ou mais objetos de estudo: professores, } \\
\text { alunos do ensino médio, professores em } \\
\text { formação, alunos do ensino fundamental, } \\
\text { livros didáticos, professores e alunos, alunos } \\
\text { de bacharelado, materiais produzidos pelo } \\
\text { professor, cientistas, jornais e meios de } \\
\text { comunicação em geral, vídeos (desenhos, } \\
\text { filmes e documentários), diretrizes curriculares, } \\
\text { público em geral. }\end{array}$ \\
\hline & $\begin{array}{l}\text { Origem geográfica do } \\
\text { objeto de estudo. }\end{array}$ & $\begin{array}{l}\text { Nacionalidade do que está sendo investigado } \\
\text { no estudo (por exemplo, público, livro/material } \\
\text { didático). }\end{array}$ \\
\hline
\end{tabular}

Figura 3. Categorias de classificação dos artigos, conforme os objetivos da revisão (continua) 


\begin{tabular}{|l|l|l|}
\hline Pergunta da revisão & Descrição da categoria & Divisões das categorias \\
\hline $\begin{array}{l}\text { (iii) Quais aspectos } \\
\text { de NdC costumam } \\
\text { ser elencados como } \\
\text { importantes para o } \\
\text { ensino nesses trabalhos? }\end{array}$ & $\begin{array}{l}\text { Relação dos aspectos } \\
\text { relatados nos artigos, } \\
\text { independentemente do } \\
\text { número de vezes que o } \\
\text { aspecto de NdC aparece. }\end{array}$ & \\
\hline $\begin{array}{l}\text { (iv) Quais as principais } \\
\text { estratégias usadas para } \\
\text { acessar as concepções de } \\
\text { NdC? }\end{array}$ & $\begin{array}{l}\text { Tipo da estratégia, com uso } \\
\text { ou não de um instrumento } \\
\text { de pesquisa. }\end{array}$ & $\begin{array}{l}\text { Em caso de uso de um instrumento de } \\
\text { pesquisa, qual o nome do instrumento } \\
\text { usado no artigo. }\end{array}$ \\
\hline
\end{tabular}

Figura 3. Categorias de classificação dos artigos, conforme os objetivos da revisão

\section{Resultados e Discussão}

\section{Quais as tendências de publicação dos trabalhos sobre concepções de NdC?}

A identificação dos periódicos das áreas de Ensino e Educação da lista WebQualis 2013 resultou numa nova lista com 198 periódicos (Figura 2, etapa de Identificação. Os periódicos estão listados no Apêndice ao final do artigo). Encontramos artigos sobre concepções de $\mathrm{NdC}$ em 61 periódicos, dos quais 19 são brasileiros. Após a seleção e a triagem (Figura 2), obtivemos 396 artigos. O estrato A1 teve as maiores ocorrências de artigos, representando 70,7\% da amostragem (Número de artigos $=\mathrm{N}_{\mathrm{A}}=280$ ). Nos periódicos A2 e B1 registramos 12,6\% $\left(\mathrm{N}_{\mathrm{A}}=50\right)$ e 14,7\% $\left(\mathrm{N}_{\mathrm{A}}=58\right)$, respectivamente, nos periódicos $\mathrm{B} 2$ apenas $2 \%\left(\mathrm{~N}_{\mathrm{A}}=8\right)$ e nos $\mathrm{B} 3$, nenhum.

O artigo Science Teaching and the Nature of Science (Robinson, 1965) foi o mais antigo que emergiu da nossa amostragem. Registramos um crescimento dos estudos sobre concepções de $\mathrm{NdC}$ (Figura 4), tanto com base nas publicações dos periódicos da WebQualis 2013, quanto nas publicações da Web of Science. Entretanto, a lista WebQualis parece ser mais inclusiva (para os termos de busca que usamos), podendo dar uma melhor noção quantitativa da produção da área para o período pesquisado. Ao responder nossas questões de revisão, nas seções seguintes, procuramos pontuar de que forma a presente revisão fornece indícios da ampliação do escopo de revisões tradicionais publicadas anteriormente. 


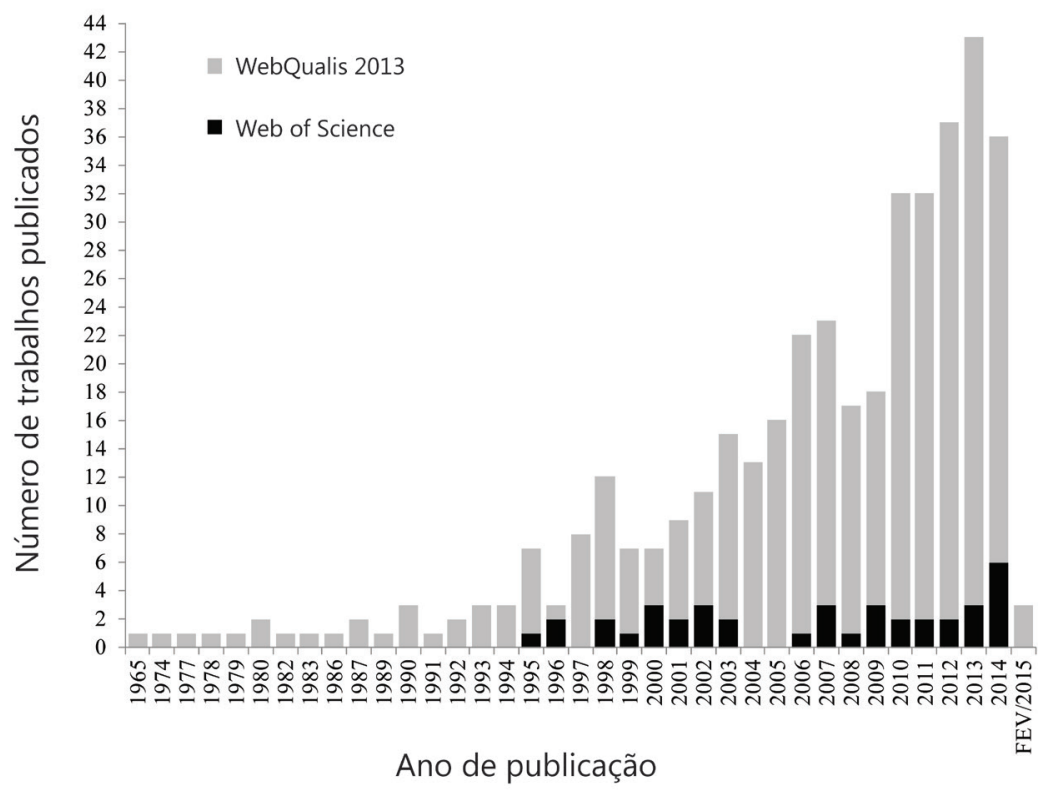

Figura 4. Comparação do número de artigos sobre concepções de NdC publicados anualmente, (desde a primeira incidência até fevereiro de 2015) nos periódicos dos estratos A1 a B3, das áreas de Ensino e Educação, da lista WebQualis 2013 (em cinza) e em periódicos indexados na base de dados da Web of Science (em preto).

\section{Quais as características dos trabalhos sobre concepções de NdC?}

Existe uma variação no interesse quanto à investigação de concepções de $\mathrm{NdC}$ conforme a área do conhecimento (Tabela 1). Os artigos associados aos periódicos com a temática de ensino de ciências (sem detalhar uma das ciências da natureza) predominaram, representando $64,7 \%$ dos estudos sobre concepções de $\mathrm{NdC}$. Tal fato é compreensível, pois o escopo desses periódicos envolve uma temática mais ampla e voltada para diversos níveis de ensino. Os periódicos associados ao ensino de Biologia foram os que tiveram o menor número de artigos, representando menos de $10 \%$ dos artigos sobre concepções de $\mathrm{NdC}$ amostrados. Os periódicos de ensino de Física publicaram o dobro de artigos sobre o tema, em comparação com os de ensino de Biologia, no mesmo período.

Tabela 1. Área do conhecimento envolvida nas investigações sobre concepções de $\mathrm{NdC}$, conforme os artigos publicados até fevereiro de 2015 nos periódicos dos estratos A1 a B3 da lista WebQualis 2013 das áreas de Ensino e Educação.

\begin{tabular}{lcc}
\hline Área associada ao estudo & Número de artigos & Proporção (\%) \\
\hline Ciências em geral & 256 & 64,7 \\
Física & 58 & 14,6 \\
Química & 53 & 13,4 \\
Biologia & 29 & 7,3 \\
\hline
\end{tabular}


No contexto Brasileiro, a área de ensino de Física é mais antiga quando comparada ao ensino de Biologia, fato que poderia estar relacionado com uma maior tradição em pesquisas na área de ensino de Física. Tal esforço pode, ainda, estar relacionado à tentativa dos pesquisadores do ensino de Física para lidar com o comum distanciamento dos estudantes em disciplinas de exatas.

$\mathrm{O}$ número reduzido de artigos de $\mathrm{NdC}$ associados à área de Biologia merece atenção, sobretudo quando consideramos que a Biologia contempla uma variedade de ciências (Botânica, Zoologia, Fisiologia, Genética, Ecologia, Evolução, etc.), com métodos e práticas particulares. Identificar o interesse dos pesquisadores das diversas ciências nos parece adequado, pois cada área carrega uma parcela de idiossincrasia, podendo considerar certos aspectos de $\mathrm{NdC}$ mais ou menos importantes. A exemplo, citamos a diferenciação de leis e teorias, que pode fazer sentido para áreas como a Física, mas é discutível para a Biologia (p. ex., Mayr, 2004; Rosenberg, 2008). Na mesma linha, é possível pensar no papel de destaque da experimentação para algumas áreas da Biologia e da Química. Entretanto, tais práticas não são as únicas contempladas como métodos da ciência. Há outras formas de produzir conhecimento científico, como os estudos de casos (Shrader-Frechette \& MacCoy, 1994), presentes nas ciências naturais e sociais (Bayir, Cakici, \& Ertas, 2014) e os estudos comparativos (Shrader-Frechette \& MacCoy, 1993). Apesar disso, historicamente, certas práticas de sala de aula e muitos materiais didáticos de Biologia, por exemplo, reforçam uma visão distorcida da área, privilegiando a imagem de que ciência só se faz com experimentação (Marandino, Selles, \& Ferreira, 2009). Pontuamos, então, que é necessário um maior investimento dos pesquisadores da área de ensino de Biologia para a investigação de concepções e aspectos de $\mathrm{NdC}$, de forma a contribuir para a reflexão sobre as diferentes dimensões dos objetivos do ensino de ciências também no ensino de Biologia.

Quanto aos tipos de artigos, 57,8\% são de levantamento de concepções de NdC de um grupo (Tabela 2). Há artigos (35\%) em que os autores expõem seus posicionamentos (i) a favor de abordagens que melhorem as concepções de $\mathrm{NdC}$ de um público, (ii) advogando sobre a inclusão de determinados aspectos de $\mathrm{NdC}$ nos currículos (discussão que apresentamos melhor na seção Quais aspectos de NdC costumam ser elencados como importantes para o ensino de ciências?, mais adiante), (iii) criticando metodologias para acessar as concepções de $\mathrm{NdC}$, ou ainda (iv) primordialmente dialogando com outros trabalhos. Em outros artigos (4\%), os autores se propuseram a fazer uma revisão tradicional da área, incluindo, segundo eles, referências-chave sobre o assunto e explorando-as criticamente. Um pequeno número de artigos (2,3\%) esteve focado em apresentar um instrumento novo para acessar concepções de $\mathrm{NdC}$.

Embora a criação de novos instrumentos não seja uma tarefa trivial, por demandar rigor tanto na elaboração quanto na validação dos mesmos, esperávamos que esse número fosse maior, dado que há uma preocupação crescente na literatura sobre as limitações dos instrumentos existentes levando-nos a questionar sobre a necessidade de elaborar instrumentos mais sensíveis. Sobre essa temática, procuramos apresentar um 
panorama mais contextualizado na seção Quais os principais instrumentos usados para acessar as concepções de NdC?, apresentada posteriormente. Menos de 1\% dos artigos tiveram como objetivo quantificar publicações com algum recorte específico (escolheram algum evento/encontro científico ou periódico para a amostragem e análise). De fato, o maior número de artigos sobre concepções de $\mathrm{NdC}$ está centrado no levantamento de concepções (conforme relatado na revisão tradicional do Lederman, 2007). Entretanto, uma parcela significativa também está preocupada em discutir especificamente os trabalhos produzidos na área, fazendo recortes como: comentários sobre os resultados de uma seleção de artigos, discussão sobre elementos de $\mathrm{NdC}$ que devem fazer parte dos currículos, ou, ainda, estratégias para melhorar as concepções de $\mathrm{NdC}$ de um grupo.

Tabela 2. Tipos de artigos sobre concepções de NdC publicados até fevereiro de 2015 nos periódicos dos estratos A1 a B3 da lista WebQualis 2013 das áreas de Ensino e Educação.

\begin{tabular}{lcc}
\hline Tipo de artigo & Número de artigos & Proporção (\%) \\
\hline Levantamento de concepções de NdC de um grupo & 229 & 57,8 \\
Posicionamento teórico & 139 & 35,1 \\
Revisão tradicional da literatura & 16 & 4,0 \\
Criação de instrumento & 9 & 2,3 \\
Outros tipos de revisão de literatura & 3 & 0,8 \\
\hline
\end{tabular}

Em números absolutos de artigos levantados e categorizados, a presente revisão apresenta indícios quantitativos de ter ampliado o escopo de revisões anteriores, sobretudo quanto ao entendimento de em que contextos esforços adicionais de pesquisa podem ser necessários. Um primeiro ponto de destaque é que não encontramos revisões sistemáticas relacionadas à área de $\mathrm{NdC}$ (Tabela 2). As revisões que encontramos analisaram um número restrito de artigos, publicados em língua inglesa, ou artigos disponíveis em anais de eventos científicos. Adicionalmente, os artigos de revisão tradicional da literatura representaram um percentual baixo no número de artigos totais, sobretudo ao considerarmos que o artigo mais antigo do nosso levantamento data de mais de 60 anos de publicação. Embora as revisões tradicionais sejam de extrema importância por trazerem discussões críticas e pertinentes para a área, o fato de os autores não explicitarem seus critérios de seleção para os trabalhos discutidos pode incorrer em vieses substanciais, sobretudo ao considerarem trabalhos produzidos por um determinado grupo de pesquisadores. Do nosso levantamento, destacamos as revisões tradicionais de Lederman (1992), Koulaidis e Ogborn (1995) e Harres (1999), cujos comentários trazemos em alguns pontos da nossa discussão.

Lederman (1992) traz um panorama de alguns trabalhos empíricos de levantamento de concepções de $\mathrm{NdC}$ de estudantes e professores produzidos nos 40 anos que antecederam a publicação do artigo (conforme checamos na relação das referências bibliográficas do artigo). $\mathrm{O}$ autor revisou os resultados de cerca de vinte trabalhos relacionados com concepções de estudantes, além de trazer uma discussão sobre as possíveis implicações das concepções de $\mathrm{NdC}$ de professores para o ensino de 
ciências. Dentre as principais conclusões da revisão de Lederman, ele destacou que (i) os professores de ciências não possuem concepções adequadas de $\mathrm{NdC}$; (ii) a formação acadêmica dos professores não apresenta relação com as concepções de $\mathrm{NdC}$ que eles possuem; e (iii) a melhoria das concepções de professores esteve associada a estratégias que envolveram história da ciência e atenção à NdC.

Quanto ao foco de estudo nos artigos de levantamento das concepções de $\mathrm{NdC}$ (Tabela 3), cerca de 30\% dos estudos são voltados para as concepções de professores da educação básica. Desses, 22,5\% são de levantamento das concepções de $\mathrm{NdC}$ de professores, enquanto $7,1 \%$ são de comparações entre as concepções de $\mathrm{NdC}$ de professores e de seus alunos. Cerca de 32\% dos artigos focam nas concepções de $\mathrm{NdC}$ dos alunos (ensino médio e fundamental) e uma parcela menor se ocupa de materiais didáticos e materiais instrucionais (como planejamento de aulas, listas de exercícios, trabalhos, atividades investigativas e roteiros de laboratório) produzidos pelo professor.

Tabela 3. Foco de estudo nos artigos de levantamento de concepções de NdC publicados até fevereiro de 2015 nos periódicos dos estratos A1 a B3 da lista WebQualis 2013 das áreas de Ensino e Educação.

\begin{tabular}{lcc}
\hline Foco de estudo & Número de artigos & Proporção (\%) \\
\hline Professores & 89 & 22,5 \\
Alunos do ensino médio & 67 & 16,9 \\
Professores em formação & 63 & 15,9 \\
Alunos do ensino fundamental & 62 & 15,7 \\
Livros didáticos & 39 & 9,8 \\
Professores e alunos & 28 & 7,1 \\
Alunos de bacharelado & 17 & 4,3 \\
Materiais produzidos pelo professor & 10 & 2,5 \\
Cientistas (de todas as áreas do conhecimento) & 7 & 1,7 \\
Jornais e meios de comunicação em geral & 5 & 1,3 \\
Vídeos (desenhos, filmes e documentários) & 4 & 1,0 \\
Diretrizes curriculares & 3 & 0,8 \\
Público em geral & 2 & 0,5 \\
\hline
\end{tabular}

O foco dos artigos de levantamento de concepções de NdC está notavelmente na educação básica. Além dos artigos que estão focados nos professores e alunos, há ainda uma parcela investigando concepções de $\mathrm{NdC}$ de professores em formação (15,9\%). Poucos levantamentos têm o objetivo de mapear o que é divulgado fora da sala de aula, investigando as concepções de $\mathrm{NdC}$ presentes na mídia $(2,4 \%)$ e as do público em geral $(0,5 \%)$. Os artigos que buscam verificar os possíveis consensos entre diversas áreas do conhecimento e avaliam as concepções de $\mathrm{NdC}$ de cientistas e das diretrizes curriculares também representam uma parcela restrita $(2,5 \%)$.

Ainda sobre o foco dos artigos, a revisão tradicional de Lederman (1992), citou trabalhos publicados entre 1950 a 1991, em cerca de dez periódicos de língua 
inglesa. O autor propôs uma classificação dos estudos sobre concepções de $\mathrm{NdC}$ em quatro categorias: (i) trabalhos sobre concepções de NdC de estudantes; (ii) trabalhos sobre concepções de $\mathrm{NdC}$ de professores; (iii) trabalhos sobre concepções de $\mathrm{NdC}$ nos currículos; e (iv) trabalhos relacionando as implicações da práxis do professor com as concepções de $\mathrm{NdC}$ de seus estudantes. A presente revisão tem um foco diferente do da revisão de Lederman, que partiu dos princípios de uma revisão tradicional e pretendeu olhar especificamente para os resultados de um grupo de trabalhos selecionados por ele. Nas considerações finais, Lederman afirmou que há uma expectativa de que o professor possa promover alterações nas concepções de $\mathrm{NdC}$ dos estudantes, ainda que eles também possuam concepções inadequadas ou conflitantes com as concepções de ciência desejadas segundo os currículos de ensino de ciências até aquela época. Da revisão do Lederman (1992) até janeiro de 2015, houve um aumento significativo de trabalhos, conforme evidenciado na Figura 4.

Em nosso levantamento, o número reduzido de artigos investigando as concepções de $\mathrm{NdC}$ de alunos de bacharelado e de cientistas foi outro dado que nos chamou a atenção. Embora o interesse pelas concepções de $\mathrm{NdC}$ relacionadas à educação básica seja essencial, dado os objetivos do ensino de ciências, a compreensão de ciência em outros níveis de ensino não pode ser deixada de lado. Investigar as concepções de $\mathrm{NdC}$ de estudantes de cursos de bacharelado e de cientistas é relevante pois permite detectar o modo como esse grupo enxerga a construção do conhecimento e como certos mitos podem estar enraizados também no ambiente acadêmico (Feldman, Divoll, \& RoganKlyve, 2013; Harding \& Hare, 2000).

Os países cujas concepções de $\mathrm{NdC}$ são mais investigadas (entre diferentes públicos, livros/material didático) são Estados Unidos e Taiwan (Tabela 4). O Brasil ocupa a quarta posição, juntamente com a Inglaterra (com 7\% dos trabalhos cada um). Embora tenhamos concentrado esforços para amostrar periódicos latino-americanos com a escolha da lista WebQualis 2013, tal esforço não foi refletido em uma numeração absoluta alta de artigos com foco de estudo em públicos ou materiais latino-americanos. Por outro lado, tal decisão resultou no fato de a lista de periódicos incluir uma maior variação de nacionalidades na amostragem, dando representatividade (ainda que pequena) a outros países (Tabela 4). 
Tabela 4. Países nos quais as concepções de NdC (de diferentes públicos ou materiais didáticos) foram investigadas nos 229 artigos de levantamento de concepções de $\mathrm{NdC}$ publicados até fevereiro de 2015 nos periódicos dos estratos A1 a B3 da lista WebQualis 2013 das áreas de Ensino e Educação.

\begin{tabular}{llcc}
\hline & Países & Número de artigos & Proporção (\%) \\
\hline 1 & Estados Unidos & 48 & 21,0 \\
2 & Taiwan & 24 & 10,5 \\
3 & China & 17 & 7,4 \\
$4^{*}$ & Brasil, Inglaterra & $16^{*}$ & $7,0^{*}$ \\
5 & Turquia & 13 & 5,7 \\
6 & Canadá & 11 & 4,8 \\
7 & Argentina & 10 & 4,4 \\
8 & Espanha & 9 & 3,9 \\
9 & África do Sul & 8 & 3,5 \\
$10^{*}$ & Colômbia, México & $7^{*}$ & $3,1^{*}$ \\
11 & Alemanha & 6 & 2,6 \\
$12^{*}$ & Coreia do Sul, Israel & $5^{*}$ & $2,2^{*}$ \\
$13^{*}$ & Austrália, Nigéria & $3^{*}$ & $1,3^{*}$ \\
$14^{*}$ & Chipre, Egito, Holanda, Índia, Japão, Portugal & $2^{*}$ & $0,9^{*}$ \\
$15^{*}$ & Arábia Saudita, Bolívia, Cingapura, Emirados Árabes & $1^{*}$ & $0,4^{*}$ \\
\hline & Unidos, Filipinas, Irã, Noruega, Nova Zelândia, Tailândia & & \\
\hline
\end{tabular}

$\left.{ }^{*}\right]$ As linhas com mais de um país indicam o número de artigos e a proporção para cada um deles.

\section{Quais aspectos de NdC costumam ser elencados como importantes para o ensino de ciências?}

Para identificar os aspectos de $\mathrm{NdC}$ considerados relevantes, partirmos dos 229 artigos de levantamento de concepções. Em cerca de $48 \%$ desses artigos $\left(\mathrm{N}_{\mathrm{A}}=109\right)$, os autores dedicaram-se à discussão dos aspectos de $\mathrm{NdC}$ que foram investigados ao longo do trabalho (Tabela 5). Em $36 \%$ dos artigos $\left(\mathrm{N}_{\mathrm{A}}=83\right.$ ), os autores partiram de listas de aspectos de $\mathrm{NdC}$ para analisar as concepções de $\mathrm{NdC}$ de um público, mas as implicações desses aspectos não foram discutidas com base no público pesquisado. Nos $16 \%$ dos artigos de levantamento de concepções de $\mathrm{NdC}$ restantes $\left(\mathrm{N}_{\mathrm{A}}=37\right)$, os autores não explicitaram os aspectos de $\mathrm{NdC}$ que foram investigados.

Com base nos 192 artigos que consideraram listas de aspectos de NdC para levantar concepções, organizamos os aspectos que costumam ser investigados e considerados como relevantes para o ensino. Para esse grupo de artigos, os autores que foram usados como referenciais para justificar a inclusão de determinado aspecto de $\mathrm{NdC}$ também foram identificados e incluídos em nossa síntese (Figura 5). Independentemente do número de vezes que um determinado aspecto apareceu nesse conjunto de trabalhos, ele 
foi incluído na relação que apresentamos aqui, dado que nosso objetivo foi evidenciar a diversidade de aspectos destacados na literatura e quais são os autores frequentemente utilizados para justificar os aspectos de $\mathrm{NdC}$.

Tabela 5. Abordagens utilizadas pelos autores para discutir aspectos de NdC, nos 229 artigos de levantamento de concepções de NdC publicados até fevereiro de 2015 nos periódicos dos estratos A1 a B3 da lista WebQualis 2013 das áreas de Ensino e Educação.

\begin{tabular}{lcc}
\hline Abordagem utilizada pelos autores & Número de artigos & Proporção (\%) \\
\hline $\begin{array}{l}\text { Uso de listas de aspectos de NdC, com discussão } \\
\text { dos aspectos de NdC investigados }\end{array}$ & 109 & 47,6 \\
$\begin{array}{l}\text { Uso de listas de aspectos de NdC, ausência de } \\
\text { discussão dos aspectos de NdC investigados }\end{array}$ & 83 & 36,2 \\
Não explicitaram os aspectos de NdC investigados & 37 & 16,2 \\
\hline
\end{tabular}

\begin{tabular}{|l|l|}
\hline Aspecto de NdC & Referências nas quais a inclusão do aspecto foi justificada \\
\hline $\begin{array}{l}\text { A produção do conhecimento } \\
\text { científico envolve curiosidade, } \\
\text { criatividade e imaginação. }\end{array}$ & $\begin{array}{l}\text { Aikenhead \& Ryan (1992), Alters (1997), McComas \& Olson } \\
\text { (1998), Smith \& Scharmann (1999), Gil-Pérez et al. (2001), } \\
\text { Lederman et al. (2002), Osborne et al. (2003), McComas (2006), } \\
\text { Lederman (2007), Allchin (2011), Irzik \& Nola (2011), Abd-El- } \\
\text { Khalick (2012). }\end{array}$ \\
\hline $\begin{array}{l}\text { O conhecimento científico é } \\
\text { temporário e provisório. } \\
\text { (1998), Smith \& Scharmann (1999), Gil-Pérez et al. (2001), } \\
\text { Lederman et al. (2002), Osborne et al. (2003), McComas (2006), } \\
\text { Lederman (2007), Allchin (2011), Irzik \& Nola (2011), Abd-El- } \\
\text { Khalick (2012). }\end{array}$ \\
\hline $\begin{array}{l}\text { A ciência não responde a } \\
\text { todas as perguntas, pois seus } \\
\text { métodos são limitados. }\end{array}$ & $\begin{array}{l}\text { Aikenhead \& Ryan (1992), Alters (1997), McComas \& Olson } \\
\text { (1998), Smith \& Scharmann (1999), Gil-Pérez et al. (2001), } \\
\text { Lederman et al. (2002), Osborne et al. (2003), McComas (2006), } \\
\text { Lederman (2007), Allchin (2011), Irzik \& Nola (2011), Abd-El- } \\
\text { Khalick (2012). }\end{array}$ \\
\hline $\begin{array}{l}\text { O conhecimento científico } \\
\text { é dependente do contexto } \\
\text { histórico, político, social e } \\
\text { cultural. }\end{array}$ & $\begin{array}{l}\text { Aikenhead \& Ryan (1992), McComas \& Olson (1998), Smith \& } \\
\text { Scharmann (1999), Gil-Pérez et al. (2001), Lederman et al. (2002), } \\
\text { Osborne et al. (2003), McComas (2006), Lederman (2007), Allchin } \\
\text { (2011), Irzik \& Nola (2011), Abd-El-Khalick (2012). }\end{array}$ \\
\hline $\begin{array}{l}\text { A ciência parte de observações } \\
\text { e usa inferências, cada } \\
\text { uma com características } \\
\text { específicas. }\end{array}$ & $\begin{array}{l}\text { Aikenhead \& Ryan (1992), Alters (1997), McComas \& Olson } \\
\text { (1998), Smith \& Scharmann (1999), Lederman et al. (2002), } \\
\text { Osborne et al. (2003), McComas (2006), Lederman (2007), Allchin } \\
\text { (2011), Irzik \& Nola (2011), Abd-El-Khalick (2012). }\end{array}$ \\
\hline
\end{tabular}

Figura 5. Relação de aspectos de NdC presentes nos 192 artigos de levantamento de concepções de $\mathrm{NdC}$ e referências nas quais eles foram justificados, conforme levantamento nos artigos de concepções de NdC publicados até fevereiro de 2015 nos periódicos dos estratos A1 a B3 da lista WebQualis 2013 das áreas de Ensino e Educação (continua) 


\begin{tabular}{|c|c|}
\hline Aspecto de $\mathrm{NdC}$ & Referências nas quais a inclusão do aspecto foi justificada \\
\hline $\begin{array}{l}\text { A ciência busca por dados de } \\
\text { acordo com as teorias. }\end{array}$ & $\begin{array}{l}\text { Aikenhead \& Ryan (1992), Alters (1997), Gil-Pérez et al. (2001), } \\
\text { Lederman et al. (2002), Osborne et al. (2003), Lederman (2007), } \\
\text { Allchin (2011), Irzik \& Nola (2011), Abd-El-Khalick (2012). }\end{array}$ \\
\hline $\begin{array}{l}\text { A ciência pode ser embasada } \\
\text { no empirismo. }\end{array}$ & $\begin{array}{l}\text { Aikenhead \& Ryan (1992), McComas \& Olson (1998), Smith \& } \\
\text { Scharmann (1999), Lederman et al. (2002), Osborne et al. (2003), } \\
\text { McComas (2006), Allchin (2011), Irzik \& Nola (2011), Abd-El- } \\
\text { Khalick (2012). }\end{array}$ \\
\hline $\begin{array}{l}\text { O conhecimento científico é } \\
\text { construído por leis e teorias, } \\
\text { cada uma com características e } \\
\text { limitações específicas. }\end{array}$ & $\begin{array}{l}\text { Aikenhead \& Ryan (1992), Smith \& Scharmann (1999), Lederman } \\
\text { et al. (2002), Osborne et al. (2003), McComas (2006), Lederman } \\
\text { (2007), Irzik \& Nola (2011), Abd-El-Khalick (2012). }\end{array}$ \\
\hline $\begin{array}{l}\text { O conhecimento científico } \\
\text { é construído a partir de } \\
\text { múltiplos métodos. }\end{array}$ & $\begin{array}{l}\text { Aikenhead \& Ryan (1992), Alters (1997), Gil-Pérez et al. (2001), } \\
\text { Lederman et al. (2002), Osborne et al. (2003), Allchin (2011), Irzik } \\
\text { \& Nola (2011). }\end{array}$ \\
\hline $\begin{array}{l}\text { A ciência busca a } \\
\text { replicabilidade e a confiança } \\
\text { nos dados. }\end{array}$ & $\begin{array}{l}\text { McComas \& Olson (1998), Smith \& Scharmann (1999), Osborne } \\
\text { et al. (2003), Allchin (2011), Irzik \& Nola (2011). }\end{array}$ \\
\hline $\begin{array}{l}\text { A ciência busca a } \\
\text { sistematização, obediência a } \\
\text { regras e uma coerência geral. }\end{array}$ & $\begin{array}{l}\text { Aikenhead \& Ryan (1992), Alters (1997), Smith \& Scharmann } \\
\text { (1999), Gil-Pérez et al. (2001), Allchin (2011). }\end{array}$ \\
\hline A ciência é subjetiva. & $\begin{array}{l}\text { Aikenhead \& Ryan (1992), Lederman et al. (2002), McComas } \\
\text { (2006), Lederman (2007), Allchin (2011). }\end{array}$ \\
\hline $\begin{array}{l}\text { A ciência desenvolve-se a partir } \\
\text { de cooperação e colaboração. }\end{array}$ & $\begin{array}{l}\text { Gil-Pérez et al. (2001), Osborne et al. (2003), Allchin (2011), Abd- } \\
\text { El-Khalick (2012). }\end{array}$ \\
\hline $\begin{array}{l}\text { A ciência não é obra de gênios } \\
\text { isolados. }\end{array}$ & $\begin{array}{l}\text { Gil-Pérez et al. (2001), Osborne et al. (2003), Allchin (2011), Abd- } \\
\text { El-Khalick (2012). }\end{array}$ \\
\hline $\begin{array}{l}\text { A ciência baseia-se na } \\
\text { argumentação. }\end{array}$ & $\begin{array}{l}\text { Alters (1997), Smith \& Scharmann (1999), Lederman (2007), } \\
\text { Allchin (2011). }\end{array}$ \\
\hline $\begin{array}{l}\text { A ciência busca pela síntese e } \\
\text { não apenas por análises, isto } \\
\text { é, busca a simplificação do } \\
\text { conhecimento. }\end{array}$ & Alters (1997), Gil-Pérez et al. (2001), Osborne et al. (2003). \\
\hline A ciência difere da tecnologia. & $\begin{array}{l}\text { Aikenhead \& Ryan (1992), McComas \& Olson (1998), McComas } \\
(2006) .\end{array}$ \\
\hline $\begin{array}{l}\text { A ciência baseia-se no } \\
\text { conhecimento cumulativo e } \\
\text { não linear. }\end{array}$ & Aikenhead \& Ryan (1992), Gil-Pérez et al. (2001). \\
\hline $\begin{array}{l}\text { A ciência baseia-se em } \\
\text { hipóteses. }\end{array}$ & Gil-Pérez et al. (2001), Osborne et al. (2003). \\
\hline
\end{tabular}

Figura 5. Relação de aspectos de NdC presentes nos 192 artigos de levantamento de concepções de $\mathrm{NdC}$ e referências nas quais eles foram justificados, conforme levantamento nos artigos de concepções de NdC publicados até fevereiro de 2015 nos periódicos dos estratos A1 a B3 da lista WebQualis 2013 das áreas de Ensino e Educação (continua) 


\begin{tabular}{|l|l|}
\hline Aspecto de NdC & Referências nas quais a inclusão do aspecto foi justificada \\
\hline $\begin{array}{l}\text { A ciência busca pela ordenação } \\
\text { do mundo físico. }\end{array}$ & Alters (1997), McComas \& Olson (1998) \\
\hline $\begin{array}{l}\text { A ciência busca explicar } \\
\text { fenômenos. }\end{array}$ & Alters (1997), McComas \& Olson (1998) \\
\hline $\begin{array}{l}\text { A ciência deve ter uma } \\
\text { divulgação clara e aberta. }\end{array}$ & McComas \& Olson (1998), Allchin (2011). \\
\hline $\begin{array}{l}\text { A ciência assume que existe } \\
\text { um mundo independente da } \\
\text { observação. }\end{array}$ & Alters (1997) \\
\hline $\begin{array}{l}\text { A ciência parte da ausência de } \\
\text { um criador. }\end{array}$ & Alters (1997) \\
\hline $\begin{array}{l}\text { A ciência possui implicações } \\
\text { globais. }\end{array}$ & McComas \& Olson (1998) \\
\hline
\end{tabular}

Figura 5. Relação de aspectos de NdC presentes nos 192 artigos de levantamento de concepções de $\mathrm{NdC}$ e referências nas quais eles foram justificados, conforme levantamento nos artigos de concepções de NdC publicados até fevereiro de 2015 nos periódicos dos estratos A1 a B3 da lista WebQualis 2013 das áreas de Ensino e Educação

Embora a síntese que trazemos na Figura 5 tenha o papel de explicitar os aspectos de $\mathrm{NdC}$ que têm sido destacados nos trabalhos da área, ressaltamos que não faz parte do escopo deste trabalho propor uma lista de aspectos que possa ser usada na pesquisa, ou no ensino. O que pretendemos destacar aqui é que na literatura há um debate acerca de variados aspectos de $\mathrm{NdC}$ e da inclusão deles como elementos obrigatórios para a educação básica. Diante desse cenário, registramos 25 aspectos de NdC relatados como importantes para o ensino.

Para alguns autores, há um consenso sobre os aspectos que devem ser incluídos e investigados na educação básica (p. ex., Abd-El-Khalick, 2012; Lederman, 1992; Lederman, 2007; McComas, 2008; McComas e Almaznoa, 1998; Osborne, Collins, Ratcliffe, Millar, \& Duschl, 2003; Stanley \& Brinckhouse, 2001). Para justificar sua visão como consensual, esses autores argumentam que, embora a definição de ciência ainda seja um tema em aberto sob o ponto de vista filosófico, há uma visão pedagógica corrente acerca da temática permeando os trabalhos de $\mathrm{NdC}$. A visão considerada consensual aborda aspectos presentes na Figura 5 e os artigos que amostramos exploram tais aspectos em maior ou menor grau (dependendo do artigo e dos objetivos). Destacamos que os 25 aspectos encontrados no nosso levantamento ultrapassam os aspectos adotados como consensuais por autores frequentemente citados na literatura (p. ex. Lederman et al., 2002). Os aspectos tomados como consensuais enunciam que o conhecimento científico é (i) provisório, (ii) fruto do empirismo, (iii) orientado por teorias, (iv) parcialmente dependente de inferências, criatividade e imaginação, (v) organizado em leis e teorias (que possuem naturezas distintas), (vi) produzido dentro de um contexto social e cultural e (vii) baseado em uma diversidade de métodos. Muitos dos artigos que amostramos 
trazem afirmações sobre o conhecimento científico e as misturam com diferentes características da ciência, como as epistemológicas, sociológicas e psicológicas, fato já destacado por outros autores (p. ex., Matthews, 2012) ao criticarem os aspectos que são considerados em trabalhos de levantamento de concepções de NdC.

Para Clough (2006), aspectos de NdC elencados na forma de afirmações podem ser facilmente mal compreendidos, podendo ser considerados com um relativismo extremo pelos estudantes, que podem considerar, por exemplo, que o fato de o conhecimento científico ser provisório significa dizer que ele não é confiável. Há ainda ponderações para a natureza das afirmações presentes nessa visão dita consensual, que podem trazer dificuldades de interpretação ou incorrerem em uma visão limitada de ciência. Dizer, por exemplo, que a ciência é subjetiva, não deixa claro que nos referimos ao fato de que ideias e observações nascem de um contexto teórico que pode não ser único em um dado momento histórico e que, por isso, é dependente das escolhas dos cientistas. A construção de uma hipótese, por exemplo, é dependente de um referencial teórico pré-existente (Gil-Pérez et al., 2001) e a adoção, ou não, de um determinado paradigma para embasar a hipótese pode depender de uma série de fatores associados às escolhas individuais do cientista. Do mesmo modo, ao dizer que a ciência tem um componente criativo, não estamos sendo claros quanto ao papel e à abrangência da criatividade para a produção do conhecimento.

Em geral, os autores que condenam o uso de listas de aspectos de $\mathrm{NdC}$ o fazem por considerá-las inadequadas perante os objetivos de uma educação científica crítica (Allchin, 2011; Irzik \& Nola, 2011). Há o risco de as listas de concepções serem entendidas como mais uma das muitas listas de conceitos que devem ser ensinados (ou apenas memorizados) em sala de aula ao serem seguidas de maneira literal. Ademais, o uso de listas (partindo de uma visão consensual ou não) apresenta um problema intrínseco, dado que traz a noção de finitude, uma vez que aspectos relevantes, como o papel do feminismo na ciência ou a dinâmica de produção do conhecimento entre as diferentes ciências, não apareçam nessas listas. As listas podem violar a intenção de fornecer aos alunos alternativas que sejam capazes de engajá-los em um debate crítico e auxiliá-los na formulação de seus próprios pontos de vista. Alguns críticos das listas (p. ex. Allchin, 2011; Irzik \& Nola, 2011; Clough, 2007; Matthews, 2012) argumentam que os princípios de $\mathrm{NdC}$ trazem pouco aprofundamento sobre os processos da ciência e que pouca atenção é dada para as especificidades das várias ciências.

Diante de tais ponderações, há algumas propostas para abordar $\mathrm{NdC}$ de forma diferente à enunciação de afirmações em listas. Clough (2007) traz a ideia de trabalhar com questões associadas à NdC, ao invés de princípios. Irzik e Nola (2011), ao afirmarem que há mais discordâncias do que consensos quanto aos aspectos de $\mathrm{NdC}$ relevantes para o ensino, exploram a ideia de que há ciências que compartilham características comuns e que podem ser agrupadas em famílias, sendo que algumas dessas famílias possuem sobreposições. Por outro lado, Allchin (2011) defende o emprego de $\mathrm{NdC}$ via contextualização, a partir de estudos de caso que abordem a confiabilidade da prática 
científica, além de outros aspectos internos da produção do conhecimento que geralmente ficam de fora das listas de concepções, como a credibilidade e a revisão por pares. Na mesma linha, Matthews (2012) defende uma reorganização dos aspectos associados à produção do conhecimento científico em características da ciência ao invés de aspectos de $N d C$, a fim de evitar a mistura de características epistemológicas, sociológicas e afins numa lista, e a associação do aprendizado de NdC à capacidade dos estudantes em identificar afirmações declarativas sobre a NdC.

Para além do debate sobre a existência de uma visão consensual e do uso, ou não, de listas, alguns autores convidam para a reflexão da real necessidade de incluir conteúdos de $\mathrm{NdC}$ nos currículos sem que haja a explicitação de suas contribuições para o desenvolvimento do indivíduo e para a sociedade (p. ex., Davson-Galle, 2008). Quanto a isso, Hodson (1994) pontua que os aspectos de $\mathrm{NdC}$ precisam estar relacionados com outros objetivos educacionais. Assim, a temática NdC pode ser explorada junto com os aspectos que motivam os alunos a adotar uma postura positiva perante a ciência, ou junto com os aspectos que ajudam na resolução de problemas complexos, tais como questões sociocientíficas. Nesse sentido, Matthews (1998) afirma que os objetivos da introdução de história e filosofia da ciência para trabalhar os aspectos de $\mathrm{NdC}$ precisam ser modestos. Para ele, embora tal abordagem possa humanizar a ciência e contribuir para superar um ensino sem sentido, não podemos esperar que os alunos resolvam grandes debates epistemológicos, mas que compreendam os contextos e implicações de conceitos e temas científicos.

Assim, entendemos que, em contraposição aos autores que consideram os aspectos de $\mathrm{NdC}$ como uma lista de conteúdos a serem aprendidos (p. ex., Lederman et al., 2002; Schwartz, Lederman, \& Lederman, 2008), há aqueles que justificam a inclusão dos aspectos de $\mathrm{NdC}$ nos currículos pelo seu potencial de contribuir com o desenvolvimento de habilidades pelos estudantes (p. ex., Allchin, 2011). Ambientes de ensino e aprendizagem que integrem abordagens didáticas históricas, investigativas e com estudos de casos contemporâneos (Allchin et al., 2014) podem fornecer oportunidades para que os estudantes construam, utilizem e reflitam sobre aspectos de $\mathrm{NdC}$, desenvolvendo, potencialmente, uma visão mais informada sobre os processos relacionados à produção do conhecimento científico. Nessa perspectiva, com a qual concordamos, listas de aspectos de $\mathrm{NdC}$ não contribuem para que as dimensões do aprender ciências, aprender a fazer ciência, aprender sobre ciências e aprender a lidar com temas sociocientíficos sejam integralmente endereçadas em sala de aula.

\section{Quais as principais estratégias usadas para acessar as concepções de NdC?}

Há uma variedade de instrumentos desenvolvidos para acessar as concepções de $\mathrm{NdC}$, não apenas quanto à forma (entrevistas, questionários, grupos de discussão, observações de sala de aula ou análise de desenhos), mas também quanto ao foco do estudo. Encontramos instrumentos que são amplamente utilizados, além de um grande número de artigos que criaram formas de coletar dados específicas para as suas próprias 
investigações (Tabela 6). Nos 61 artigos em que os pesquisadores formularam um método próprio, não havia a intenção declarada dos autores de criar um instrumento que pudesse ser aplicado em outros contextos. As estratégias variaram entre entrevistas, questões abertas, análise de materiais produzidos por alunos e professores e combinações entre esses protocolos.

Tabela 6. Instrumentos de pesquisa utilizados para acessar as concepções de NdC, considerando os artigos publicados até fevereiro de 2015 nos periódicos dos estratos A1 a B3 da lista WebQualis 2013 das áreas de Ensino e Educação

\begin{tabular}{lcc}
\hline Instrumentos de pesquisa & Número de artigos & Proporção (\%) \\
\hline VNOS (A a E) & 64 & 27,9 \\
TOUS & 28 & 12,2 \\
VOSTS & 22 & 9,6 \\
NOSS & 11 & 4,8 \\
DAST & 11 & 4,8 \\
SEVs & 9 & 3,9 \\
SUSSI & 5 & 2,2 \\
BASSQ, CI, ENOS, ISAIA, KASSPPI, LOS, MaNS, NOSI, & 1 ocorrência para \\
NOST, SAQ, STAQ, TCNSQ, TIMSS, TUS, VaPS, VASM, & cada questionário & menor que 0,5 \\
VOS, VOSE. & $(18)$ & \\
Artigos em que os autores elaboram estratégias específicas & 61 & 26,6 \\
para seus próprios estudos. & & \\
\hline
\end{tabular}

Enunciamos que um dos nossos objetivos com a presente revisão foi identificar as principais estratégias usadas para o levantamento de concepções de $\mathrm{NdC}$, a fim de desenvolver um instrumento (relatado em Azevedo \& Scarpa, 2017) que atendesse às visões mais recentes na literatura e que considerasse que a contextualização, em detrimento de questões declarativas descontextualizadas, pode possibilitar o acesso de concepções de $\mathrm{NdC}$ mais fiéis e próximas às reais concepções dos respondentes (p. ex., Allchin, 2011). Entretanto, para além dos nossos objetivos iniciais de investigação está a possibilidade de que, tanto a forma quanto os conteúdos presentes nos instrumentos de pesquisa, dizem muito sobre o que os pesquisadores consideram importante quando se trata de NdC. Os instrumentos podem indicar tanto o que é de interesse para a pesquisa e para o ensino, quanto aquilo que ainda pode ser problemático. Considerando, ainda, que os questionários podem ser usados no contexto escolar em circunstâncias avaliativas, não podemos ignorar que os instrumentos de avaliação têm um importante papel no discurso que é construído na sala de aula (Cazden, 2001). Assim, explicitar sistematicamente tanto a forma quanto o conteúdo de tais instrumentos de pesquisa é fundamental.

O instrumento mais utilizado para levantamento de concepções de $\mathrm{NdC}$ foi o Views of Nature of Science Questionnaire (VNOS) (Lederman \& O'malley, 1990), utilizado em 64 artigos. O VNOS teve a sua primeira versão (VNOS-A) desenvolvida para alunos 
da escola secundária e é composto por sete questões abertas (como por exemplo: Existe diferença entre uma teoria e uma lei científica? Dê um exemplo que justifique sua resposta.) acompanhadas por entrevistas. Variações do VNOS tiveram origem no mesmo grupo de pesquisa, resultando em outros instrumentos: VNOS-B (Abd-El-Khalick et al., 1998), VNOS-C (Abd-El-Khalick \& Lederman, 2000), VNOS-D (Lederman \& Khishfe, 2002) e VNOS-E (Lederman \& Ko, 2004). Cada um incluiu adaptações conforme o público (o VNOS-C destina-se a professores da educação básica e o VNOS-E a crianças que não sabem ler) e o contexto de aplicação (maior ou menor tempo disponíveis), mas todos são compostos por questões abertas seguidas de entrevistas. Entre esses instrumentos, há variações estruturais quanto ao tamanho (o VNOS-B tem sete itens, enquanto o VNOS-C tem 10) e aos aspectos investigados (mais ou menos amplos). A decisão por agrupar essa "família" de questionários em um único conjunto deve-se justamente à grande semelhança teórica e estrutural entre eles. Dentre os aspectos investigados na família VNOS destacamos os seguintes: a ciência é provisória (único aspecto investigado no VNOS-A), o papel da criatividade na ciência, a natureza e as relações entre as leis e as teorias científicas, a característica empírica e inferencial da ciência, a ausência de um método único (incluído no VNOS-C) e o papel da sociedade e da cultura na ciência (incluído no VNOS-C). Tais aspectos constituem o que o grupo que os elaborou chama de visão consensual da ciência.

Embora tenha sido criado antes, o Test on Understanding Science (TOUS) (Cooley \& Klopfer, 1961) teve menos ocorrências entre os artigos amostrados, com 28 incidências (12,2\% da amostra). Ele constitui um questionário com questões de quatro alternativas, totalizando 60 itens de múltipla escolha. Os aspectos de $\mathrm{NdC}$ que são investigados incluem: a visão sobre os cientistas, quais os métodos e os objetivos da ciência e o entendimento sobre o empreendimento científico.

$\mathrm{O}$ instrumento Views on Science-Technology-Society (VOSTS) (Aikenhead \& Ryan, 1992) foi usado em 22 artigos. O questionário foi desenvolvido para alunos com idades entre 11 e 12 anos e abrange temas como a influência da sociedade na ciência e na tecnologia, a influência da ciência escolar na sociedade, a construção social do conhecimento científico, as características de um cientista e a natureza do conhecimento científico. O questionário é composto por 114 itens de múltipla escolha e não fornece um score numérico no final. $\mathrm{O}$ trabalho de desenvolvimento do instrumento levou cerca de seis anos, pois para contornar o problema de ambiguidade associada às respostas a questões fechadas e evitar a escolha forçada de um determinado item, as opções de respostas foram desenvolvidas com base em respostas escritas e entrevistas fornecidas por mais de dois mil alunos. Isso resultou em itens com até 10 posicionamentos diferentes, além de incluir as opções "Eu não entendi" e "Eu não sei o bastante sobre esse assunto para fazer uma escolha".

O Nature of Science Scale (NOSS) (Kimball, 1967) foi usado em 4,8\% dos artigos de levantamento de concepções de NdC. Seu objetivo é verificar as concepções de NdC de professores da educação básica. Ele contém 29 itens, nos quais o respondente declara, 
por meio de entrevista, se concorda, discorda ou se tem uma posição neutra diante de cada afirmação. $\mathrm{O}$ instrumento foi validado por nove educadores antes da aplicação.

Usado em 4,8\% dos estudos, o Draw-a-Scientist Test (DAST) (Chambers, 1983) é um instrumento destinado a acessar concepções de crianças e é bem diferente dos outros instrumentos, pois sua análise consiste em identificar padrões nos desenhos das crianças. Em geral, há uma tendência nesses desenhos (confirmada em artigos da nossa revisão) de representar os cientistas como uma figura masculina, que usa óculos, cercado de instrumentos de laboratório, livros e aparatos tecnológicos e (às vezes) emitindo frases como "Eureka" (Chambers, 1983). As críticas a esse instrumento consistem na incapacidade de mensurar o quanto as crianças levam a sério a atividade ou compreendem o que devem fazer. Há a possibilidade de que os alunos entendam que devem desenhar a imagem ideal de um cientista e não como o veem (Boylan, Hill, Wallace, \& Wheeler, 1992). Por esse motivo, nos artigos mais recentes que usaram o DAST, os pesquisadores incorporaram também uma etapa de entrevista, na qual as crianças podem expressar suas ideias e contar a história inspiradora dos seus desenhos (p. ex., Miller, 1993; Tucker-Raymond, Varelas, Pappas, Korzh, \& Wentland, 2007).

O Scientific Epistemological Views (SEVs) (Tsai \& Liu, 2005), usado em nove artigos, é um questionário com 19 itens, nos quais as respostas são baseadas na escala Likert de cinco pontos (Concordo Fortemente, Concordo, Neutro, Discordo, Discordo Fortemente). Dentre os aspectos investigados ao longo do instrumento estão: o papel da criatividade, o impacto cultural da ciência, a dependência das teorias científicas, a negociação social e a natureza provisória da ciência.

Outro instrumento que usa a escala Likert de cinco pontos é o Student Understanding of Science and Scientif Inquiry (SUSSI) (Liang et al., 2006), empregado em 2,2\% dos artigos. Ele é composto por seis itens seguidos por espaços em que o respondente deve justificar suas respostas. Os aspectos investigados incluem: o papel da imaginação e da criatividade ao longo da investigação cientifica, a diferença entre leis e teorias, o papel da observação e da inferência, a possibilidade de mudança nas teorias científicas e a influência sociocultural na ciência.

Muitos dos instrumentos utilizados nos artigos são frequentemente alvo de críticas devido, principalmente, às limitações para acessar as reais concepções do foco do estudo. Quanto a isso, Koulaidis e Ogborn (1995) trouxeram um olhar centrado na epistemologia da ciência para os trabalhos que revisaram. Os autores estavam preocupados em levantar e discutir os pressupostos teóricos que orientam a elaboração de instrumentos utilizados para o levantamento de concepções de $\mathrm{NdC}$. Os autores analisaram 26 artigos empíricos que usaram questionários para o levantamento de concepções de $\mathrm{NdC}$, classificaram os trabalhos em 5 categorias (indutivismo, hipotético-dedutivismo, contextualismo, relativismo e ausência de posicionamento dos autores dos trabalhos) e afirmaram que "a maioria dos estudos tendem a refletir uma imagem indutivista da ciência" (p. 278) ainda que haja evidências, segundo o levantamento que fizeram, de que professores "mantêm pontos de vista ecléticos ou mistos, aderindo a uma diversidade 
de elementos retirados de diferentes posições filosóficas" (p. 280). Apesar dos mais de 20 anos de publicação, as discussões apresentadas pelos autores permanecem atuais, sobretudo quando consideramos que grande parte dos trabalhos que eles analisaram não possuíam posicionamento quanto às visões de ciência que foram consideradas para a elaboração dos instrumentos. Assim, a revisão de Koulaidis e Ogborn (1995) aponta para questões relevantes como os fatos de (i) muitos questionários considerarem apenas um posicionamento como adequado em seus estudos; (ii) os questionários poderem não captar as concepções reais de um público; e (iii) os resultados obtidos de questionários poderem ser contrastantes com os resultados de concepções amostradas por outros meios.

Outros motivos frequentemente ponderados na literatura sobre tais limitações (p. ex., Koulaidis \& Ogborn, 1995; Lederman et al., 2002; Lederman, 2007; Ryan \& Aikenhead, 1992) são: (i) uma mesma resposta fornecida por indivíduos diferentes pode ter significados distintos; (ii) da mesma forma, o mesmo significado para indivíduos diferentes pode resultar em respostas distintas; (iii) muitos instrumentos são construídos com base no ponto de vista dos pesquisadores com um determinado posicionamento filosófico, o que pode ser inacessível para os respondentes; e (iv) o fato de os respondentes não corresponderem à visão de ciência considerada no instrumento pode fazer com que suas concepções de $\mathrm{NdC}$ sejam consideradas como incorretas ou inadequadas.

Dentre as críticas citadas, a mais contundente entre os autores é a de que os respondentes podem enfrentar dificuldades para compreender o significado de questões. Instrumentos em que as questões têm várias alternativas podem ser problemáticos, pois além da frequente semelhança entre as alternativas, há a necessidade de o respondente escolher uma, que não necessariamente é aquela com a qual ele concorda (Ryan \& Aikenhead, 1992), podendo comprometer a legitimidade das conclusões do trabalho. Usar instrumentos com questões abertas ou entrevistas pode resolver as implicações relacionadas com a ambiguidade das respostas, mas não resolve a questão do posicionamento filosófico dos pesquisadores. Para contornar esse problema, encontramos alguns trabalhos que buscaram combinar diferentes instrumentos ou, ainda, acessar as concepções de NdC por meio de práticas investigativas (p. ex., Sandoval, 2005).

Um problema associadoàvariedade deinstrumentoséa dificuldade de comparação entre os estudos, não apenas pela variedade dos formatos, mas também pela variedade de posições filosóficas dos pesquisadores. Por outro lado, o uso de um instrumento fora do contexto no qual ele foi criado deve ser feito com cautela pois, em geral, os instrumentos são desenvolvidos para um público específico e são dependentes de um contexto. Há trabalhos em que os autores optam por fazer adaptações de instrumentos convencionais, a fim de permitir aplicá-los para um público de uma faixa etária específica e, ainda assim, fazer comparações com outros estudos. Quanto a essa prática, as críticas dirigidas a certos instrumentos em particular podem ser extrapoladas na tentativa de olharmos com mais prudência para os instrumentos em geral. Por exemplo, Abd-ElKhalick e BouJaoude (1997) e Botton e Brown (1998) criticaram o questionário VOSTS, 
argumentando que ele era dependente de um contexto sociocultural (uma vez que seus itens foram derivados empiricamente de um público em particular) e que isso poderia ser limitante em outros contextos. Acreditamos que essa pode ser uma característica presente em outros questionários. Assim, é necessário o cuidado na seleção de um instrumento adequado, não apenas em termos dos objetivos pretendidos para a pesquisa, mas também considerando a idade do público e o contexto sociocultural no qual os respondentes estão inseridos.

Outro ponto passível de reflexão diz respeito às dimensões teóricas dos instrumentos. Alguns incluem questões declarativas como "O que é uma teoria?" ou "O que é um experimento?" que podem ser muito amplas ou vagas para os estudantes de diferentes níveis de ensino. Assim, não apenas o contexto, mas também a linguagem pode ser relevante para acessar concepções de NdC dos estudantes (Leach, 2000). Para Allchin (2011), a validade de alguns instrumentos precisa ser considerada com cautela. Isso porque eles podem ser ineficientes para revelar habilidades críticas e o conteúdo presente em um questionário pode ser entendido como um conjunto de conceitos novos a serem simplesmente memorizados no pós-teste e não efetivamente compreendidos pelos estudantes. Ainda sobre isso, Allchin (2011) afirma que muitos instrumentos são incapazes de evidenciar "habilidades do pensamento crítico e analítico dos alunos" ( $\mathrm{p}$. 529), o que é fundamental para que as diferentes dimensões dos objetivos do ensino de ciências sejam contempladas. Esse é um problema que também está associado ao uso descontextualizado ou literal de listas de concepções de $\mathrm{NdC}$, conforme apresentamos anteriormente.

Embora os estudos de concepções de $\mathrm{NdC}$ datem de mais de 60 anos, as críticas às listas de concepções são ainda muito recentes, passando a ganhar força apenas nas duas últimas décadas. Assim, é possível que muitas das críticas ainda não tenham sido fortemente incorporadas aos estudos e reflexões da área. Como exemplo, podemos citar os princípios que guiaram a elaboração da família de questionários VNOS, amplamente utilizados e divulgados por um grupo de pesquisadores. Os princípios de $\mathrm{NdC}$ estruturantes do VNOS apenas recentemente foram ponderados e explicitamente defendidos por seu principal grupo de pesquisa, em Schwartz e colaboradores (2012), como parte de uma discussão acalorada após as críticas trazidas no trabalho de Allchin (2011). As críticas e posicionamentos explícitos em ambas as publicações geraram uma série de artigos que passaram a dar maior relevância para tais discussões (p. ex., Duschl \& Grandy, 2013; Hodson \& Wong, 2014).

Embora o debate acerca dos métodos utilizados para acessar concepções de $\mathrm{NdC}$ seja de suma importância, não há como desconsiderarmos que qualquer método carregará consigo o risco de que a caracterização de ciência atribuída ao indivíduo seja influenciada pelo método empregado. Pretendíamos mapear os instrumentos mais utilizados e procuramos explicitar as características desse grupo. Assim, descrevemos os sete instrumentos mais usuais e que corresponderam à $65,4 \%$ daqueles utilizados nos artigos de levantamento de concepções de NdC que amostramos. Porém, a variedade 
deles não se esgota nesse número, como mostramos na Tabela 6. Características de alguns dos instrumentos menos utilizados podem ser verificadas nas revisões tradicionais de Hacieminoglu e colaboradores (2012) e Lederman (2007).

Retomamos ainda que nosso objetivo com este trabalho não foi fazer uma meta-análise dos resultados obtidos em artigos de concepções de NdC dos diferentes focos de estudo, como diversos públicos ou documentos. Há revisões tradicionais que se propuseram a sintetizar o conhecimento produzido, considerando esses diferentes focos, com base em um grupo de artigos (p. ex., Abd-El-Khalick \& Lederman 2000; Harres, 1999; Lederman, 1992, 2007). Entretanto, ressaltamos que uma análise criteriosa sobre os resultados gerados por essa diversidade de métodos e que leve em consideração os possíveis vieses nos levantamentos de concepções de $\mathrm{NdC}$ (causados pelos posicionamentos filosóficos dos autores, pelo formato dos instrumentos, ou devido ao tratamento dos dados obtidos deles) pode ser necessária para a real compreensão do que sabemos até o momento quando nos referimos às concepções de $\mathrm{NdC}$ de um grupo específicos de sujeitos.

\section{Considerações finais}

Nosso levantamento indicou que, embora haja um crescimento expressivo nas publicações sobre NdC nos últimos 60 anos, há poucos artigos de revisão de literatura, sobretudo revisões não tradicionais. $\mathrm{O}$ uso de princípios replicáveis e explícitos, como os do PRISMA, pode contribuir para elucidar contextos nos quais esforços de pesquisa ainda são necessários e para compreender o que tem sido produzido, de forma crítica e menos subjetiva, nas pesquisas na área de ensino de ciências. Esta revisão sistemática representou um esforço inicial para expor um panorama geral da área e permitiu identificar algumas tendências e lacunas nas pesquisas envolvendo concepções de NdC. As revisões anteriores foram fundamentais por sintetizar o conhecimento produzido até a data de suas publicações e tiveram enfoques distintos: Lederman (1992) focou nos resultados de algumas pesquisas sobre levantamento de concepções de $\mathrm{NdC}$ de estudantes e professores; Koulaidis e Ogborn (1995) focaram nos pressupostos epistemológicos relacionados à ciência que orientavam o levantamento de concepções de NdC; e Harres (1999) trouxe um panorama de algumas pesquisas, em particular os resultados, sobre concepções de NdC.

Nossa revisão sistemática permitiu identificar algumas lacunas, relacionadas a quais esforços de pesquisa ainda podem ser necessários. Considerando as áreas do conhecimento associadas ao ensino de ciências, registramos que os pesquisadores em ensino de Biologia têm se dedicado pouco à investigação das concepções de $\mathrm{NdC}$, em comparação com as áreas de ensino de Física e de Química, ainda que o ensino de Biologia também propague visões pouco informadas sobre a $\mathrm{NdC}$. $\mathrm{O}$ foco dos trabalhos de concepções de NdC está na educação básica, com um déficit no levantamento de concepções de NdC no ensino superior em todos os países. No Brasil, ainda há a necessidade de avançar nos estudos dessa natureza, a fim de compreender o papel do 
contexto sociocultural nas concepções de $\mathrm{NdC}$ de estudantes e professores, em todos os níveis de ensino.

Neste trabalho, trouxemos um panorama geral com diferentes visões sobre as pesquisas envolvendo concepções de $\mathrm{NdC}$. Abordamos as características dos instrumentos de pesquisa e procuramos trazer a reflexão sobre o quanto eles representam mais do que possibilidades neutras de acessar os dados. Ao refletir sobre o formato dos instrumentos usados para o levantamento de concepções, também refletimos sobre o recente debate na literatura acerca da validade ou não de uma visão consensual quanto aos aspectos de $\mathrm{NdC}$ que devem estar presentes no ensino. Apesar do debate (que tem permeado a literatura mais frequentemente apenas nos últimos anos) sobre a existência de uma possível visão consensual e da diversidade de aspectos de $\mathrm{NdC}$ frequentemente investigados, identificamos 25 aspectos presentes na literatura, número bem maior do que os sete aspectos frequentemente enunciados como consensuais em trabalhos de concepções de NdC.

Trabalhos futuros podem explorar outros aspectos internos das produções sobre NdC. Vislumbramos como caminhos frutíferos de investigação, a organização de novas revisões sistemáticas, que concentrem esforços em apenas uma questão de pesquisa ou ainda a elaboração de trabalhos com meta-análises, como por exemplo, quais as concepções de $\mathrm{NdC}$ de um determinado grupo, tomando como base os resultados de trabalhos de levantamento de concepções? Entendemos que trabalhos dessa natureza, embora ainda pouco comuns na área de Ensino, podem contribuir significativamente para a organização do conhecimento que tem sido produzido na área e podem potencializar as chances de encontrarmos respostas que permeiam muitos estudos como, por exemplo, quais estratégias didáticas podem melhorar as concepções de $\mathrm{NdC}$ de professores e estudantes.

\section{Agradecimentos}

As autoras agradecem à Coordenação de Apoio de Pessoal de Nível Superior (CAPES), pelo auxílio financeiro. Ao Programa de Pós-Graduação em Ecologia da Universidade de São Paulo, por permitir a realização do trabalho. À Profa ${ }^{\mathrm{D}}{ }^{\mathrm{a}}$ Camila de Toledo Castanho, pelas contribuições na fase inicial da revisão sistemática. Aos pareceristas anônimos e à editoria da RBPEC, pelas valiosas e cuidadosas contribuições ao presente artigo.

\section{Referências}

Abd-El-Khalick, F. (2012). Examining the sources for ours understandings about science: Enduring conflations and critical issues in research on nature of science in science education. International Journal of Science Education, 34(3), 353-374.

Abd-El-Khalick, F., Bell, R. L., \& Lederman, N. G. (1998). The nature of science and instructional practice: Making the unnatural natural. Science Education, 82(4), 417-437. 
Abd-El-Khalick, F., \& Boujaoude, S. (1997). An exploratory study of the knowledge base for science teaching. Journal of Research in Science Teaching, 34(7), 673-699.

Abd-El-Khalick, F., Boujaoude, S., Duschl, R. A., Hofstein, A., Lederman, N. G., Mamlok, R., Niaz, M., Treagust, D., \& Tuan, H. (2004). Inquiry in science education: International perspectives. Science Education, 88, 397-419.

Abd-El-Khalick, F., \& Lederman, N. G. (2000). Improving science teachers' conceptions of nature of science: a critical review of the literature. International Journal of Science Education, 22(7), 665-701.

Abd-El-Khalick, F., \& Lederman, N. G. (2000). The influence of history of science courses on students' views of nature of science. Journal of Research in Science Teaching, 37(10), 1057-1095.

Aikenhead, G., \& Ryan, A. (1992). The development of a new instrument: 'Views on Science-Technology-Society' (VOSTS). Science Education, 76, 477-492.

Ajaja, P. O. (2012). Senior Secondary School Science Teachers in Delta and Edo States Conceptualization about the Nature of Science. International Education Studies, 5(3), 67-85.

Allchin, D. (2011). Evaluating Knowledge of the Nature of (Whole) Science. Science Education, 95(3), 918-942.

Allchin, D., Andersen, H., \& Nielsen, K. (2014). Complementary approaches to teaching nature of science: Integrating inquiry, historical cases and contemporary cases in classroom practice. Science Education, 98(3), 461-486.

Alters, B. J. (1997). Whose nature of science? Journal of Research in Science Teaching, 34(1), 39-55.

Azevedo, N. H., \& Scarpa, D. L. (2017). Decisões envolvidas na elaboração e validação de um questionário contextualizado sobre concepções de natureza da ciência. Investigações em Ensino de Ciências. 22(2), 57-82.

Bayir, E., Cakici, Y., \& Ertas, O. (2014). Exploring Natural and Social Scientists' Views of Nature of Science. International Journal of Science Education, 36(8), 1286-1312.

Bell, R. L., \& Lederman, N. G. (2003). Understandings of the nature of science and decision making on science and technology based issues. Science Education, 87(3), 352377.

Botton, C., \& Brown, C. (1998). The reliability of some VOSTS items when used with pre service secondary science teachers in England. Journal of Research in Science Teaching, 35(1), 53-71.

Boylan, C. R., Hill, D. M., Wallace, A. R., \& Wheeler, A. E. (1992). Beyond stereotypes. Science Education, 76(5), 465-476. 
CAPES. (2015). Qualis Periódicos. Recuperado de http://www.capes.gov.br/avaliacao/ qualis.

Carvalho, A. M. P. (2006). Critérios estruturantes para o ensino das ciências. In A. M. P. Carvalho (Org.). Ensino de Ciências: unindo a pesquisa e a prática. (pp. 1-17). São Paulo: Pioneira Thomson Learning.

Cazden, C. B. (2001). Classroom Discourse: The Language of Teaching and Learning. (2nd ed.). New Hampshire: Heinemann.

Chambers, D. W. (1983). Stereotypic images of the scientist: The draw-a-scientist test. Science Education, 67(2), 255-265.

Clough, M. P. (2006). Learners' responses to the demands of conceptual change: considerations for effective nature of science instruction. Science \& Education, 15(5), 463-494.

Clough, M. P., \& Olson, J. K. (2008). Teaching and assessing the nature of science: An introduction. Science \& Education, 17(2-3), 143-145.

Cooley, W. W., \& Klopfer, L. E. (1961). TOUS: Test on understanding science. Princeton, NJ: Education Testing Service.

Davson-Galle, P. (2008). Why compulsory science education should not include philosophy of science. Science \& Education, 17(7), 677-716.

Duschl, R., \& Grandy, R. (2013). Two views about explicitly teaching nature of science. Science and Education, 22, 2109-2139. doi: 10.1007/s11191-012-9539-4

Feldman, A., Divoll, K. A., \& Rogan-Klyve, A. (2013). Becoming researchers: The participation of undergraduate and graduate students in scientific research groups. Science Education, 97(2), 218-243.

Figueirêdo, K. L., Justi, R. (2011). Uma proposta de formação continuada de professores de ciências buscando inovação, autonomia e colaboração a partir de referenciais integrados. Revista Brasileira de Pesquisa em Educação em Ciências, 11(1), 169-190.

Fourez, G. (1997). Scientific and Technological Literacy as a Social Practice. Social Studies of Science, 27(6), 903-936.

Freitas, D. (2008). A perspectiva curricular Ciência Tecnologia e Sociedade - CTS - no ensino de ciência. In: A. C. Pavão, D. Freitas (Org.). Quanta Ciência há no Ensino de Ciências. (pp. 229-237). São Carlos: EdUFScar.

Gil-Pérez, D., Fernández, I., Carrascosa, J., Cachapuz, A., \& Praia, J. (2001). Para uma imagem não deformada do trabalho científico. Ciência \& Educação, 7(2), 125-153.

Hacieminoglu, E., YilmazTuzun, O., \& Ertepinar, H. (2012). Development and validation of nature of science instrument for elementary school students. Education 3-13: International Journal of Primary, Elementary and Early Years Education, 42(3), 258-283. 
Harding, P., \& Hare, W. (2000). Portraying science accurately in classrooms: Emphasizing open-mindedness rather than relativism. Journal of Research in Science Teaching, 37(3), $225-235$.

Harres, J. B. S. (1999). Uma revisão de pesquisas nas concepções de professores sobre a natureza da ciência e suas implicações para o ensino. Investigações em Ensino de Ciências, $4(3), 197-211$.

Hodson, D. (1998). Science fiction: the continuing misrepresentation of science in the school curriculum. Curriculum Studies, 6(2), 191-216.

Hodson, D. (1994). Seeking directions for change: The personalization and politicization of science education. Curriculum Studies, 2(1), 71-98.

Hodson, D. (2001). Inclusion without assimilation: Science education from an anthropological and meta-cognitive perspective. Canadian Journal of Science, Mathematics and Technological Education, 1(2), 161-182.

Hodson, D. (2014). Learning science, learning about science, doing science: Different goals demand different learning methods. International Journal of Science Education, 36(15), 2534-2553.

Hodson, D., \& Wong, S.L. (2014). From the horse's mouth: Why scientists' views are crucial to nature of science understanding. International Journal of Science Education, 36(16), 2639-2665.

Irzik, G., \& Nola, R. (2011). A family resemblance approach to the nature of science for science education. Science \& Education, 20(7), 591-607.

Khishfe, R., \& AbdElKhalick, F. (2002). Influence of explicit reflective versus implicit inquiryoriented instruction on sixth graders' views of nature of science. Journal of Research in Science Teaching, 39(7), 551-578.

Khishfe, R. (2014). Explicit Nature of Science and Argumentation Instruction in the Context of Socio-scientific Issues: An effect on student learning and transfer. International Journal of Science Education, 36(6), 974-1016.

Kimball, M. E. (1967). Understanding the nature of science: A comparison of scientists and science teachers. Journal of Research in Science Teaching, 5(2), 110-120.

Knopf, J. W. (2006). Doing a literature review. PS: Political Science \& Politics, 39(1), 127132.

Koulaidis, V., \& Ogborn, J. (1995). Science teachers philosophical assumptions: How well do we understand them? International Journal of Science Education, 17(3), 273-283.

Leach, J., Millar, R., Ryder, J., \& Sére, M. G. (2000). Epistemological understanding in science learning: The consistency of representations across contexts. Learning and Instruction, 10(6), 497-527. 
Lederman, N. G. (1992). Students' and teachers' conceptions of the nature of science: A review of the research. Journal of Research in Science Teaching, 29(4), 331-359.

Lederman, N. G. (2007). Nature of science: Past, present, and future. In S. K. Abell \& N. G. Lederman (Eds.), Handbook of research on science education (pp. 831879). Mahwah, N.J: Lawrence Erlbaum Associates

Lederman, N. G., AbdElKhalick, F., Bell, R. L., \& Schwartz, R. (2002). Views of nature of science questionnaire (VNOS): Toward valid and meaningful assessment of learners' conceptions of nature of science. Journal of Research in Science Teaching, 39(6), 497-521.

Lederman, J. S., \& Khishfe, R. (2002). Views of nature of science, Form D. Unpublished paper. Illinois Institute of Technology, Chicago.

Lederman, J. S., \& Ko, E. K. (2002). Views of nature of science, Form E. Unpublished paper. Illinois Institute of Technology, Chicago.

Lederman, N. G., \& O'malley, M. (1990). Students' perceptions of tentativeness in science: Development, use, and sources of change. Science Education, 74(2), 225-239.

Lemke, J. L. (2001). Articulating Communities: Sociocultural Perspectives on Science Education. Journal of Research in Science Teaching, 38(3), 296-316.

Liang, L. L., Chen, S., Chen, X., Kaya, O. N., Adams, A. D., Macklin, M., \& Ebenezer, J. (2006). Student understanding of science and scientific inquiry (SUSSI): Revision and further validation of an assessment instrument. Paper presented at the The annual meeting of the National Association for Research in Science Teaching, San Francisco, CA.

Lidar, M., Lundqvist, E., \& Ostman, L. (2006). Teaching and learning in the science classroom: The interplay between teachers' epistemological moves and students' practical epistemology. Science Education, 90(1), 148-163.

Mayr, E. (2004). What makes biology unique? Considerations on the autonomy of a scientific discipline. Cambridge: Cambridge University Press.

Marandino, M., Selles, S. E., Ferreira, M. S. (2009). Ensino de Biologia: histórias e práticas em diferentes espaços educativos. São Paulo: Cortez.

Matthews, M. R. (1992). History, philosophy and science teaching: the present reapprochement. Science \& Education, 1(1), 11-48.

Matthews, M. R. (1998). In defense of modest goals when teaching about the nature of science. Journal of Research in Science Teaching, 35(2), 161-174.

Matthews, M. R. (2012). Changing the focus: from nature of science to features of science. In Khine, M. S. (Ed.). Advances in nature of science research (pp. 3-26). Dordrecht: Springer.

McComas, W. F. (2006). Science Teaching beyond the Classroom. Science Teacher, 73(1), 26-30. 
McComas, W. F. (2008). Seeking historical examples to illustrate key aspects of the nature of science. Science \& Education, 17(2-3), 249-263

McComas, W. F., Almazroa, H., Clough, M. (1998). The Nature of Science in Science Edu- cation: an introduction. Science \& Education, 7(6), 11-532.

McComas, W. F., \& Olson, J. K. (1998). The Nature of Science in International Science Education Standards Documents. In McComas, W. F. (Ed.). The Nature of Science in Science Education: Rationales and Strategies (pp. 41-52). Drodrecht: Kluwer.

Miller, J. D. (1993). Theory and measurement in the public understanding of science: a rejoinder to Bauer and Schoon. Public Understanding of Science, 2(3), 235-243.

Moher, D., Liberati, A., Tetzlaff, J., \& Altman, D. G. (2009). The PRISMA Group. Preferred Reporting Items for Systematic Reviews and Meta-Analyses: The PRISMA Statement. PLoS Med, 6(6). doi:10.1371/journal.pmed1000097.

Moss, D. M., Abrams, E. D., \& Robb, J. (2001). Examining student conceptions of the nature of science. International Journal of Science Education, 23(8), 771-790.

Ogunniyi, M. (2005). Relative effects of a history, philosophy and sociology of science course on teachers' understanding of the nature of science and instructional practice. South African Journal of Higher Education, 19, 1464-1472.

Osborne, J., Collins, S., Ratcliffe, M., Millar, R., \& Duschl, R. (2003). What “ideasabout science" should be taught in school science? A Delphi study of the expert community. Journal of Research in Science Teaching, 40(7), 692-720.

Packer, A. L. (2011). Os periódicos brasileiros e a comunicação da pesquisa nacional. Revista USP, 89, 26-61.

Ryan, A. G., \& Aikenhead, G. S. (1992). Students' preconceptions about the epistemology of science. Science Education, 76(6), 559-580.

Robinson, J. T. (1965). Science Teaching and the Nature of Science. Journal of Research in Science Teaching, 3(1), 37-50.

Rodrigues, R. S., Quartiero, E., \& Neubert, P. (2015). Periódicos Científicos Brasileiros indexados na Web Of Science e Scopus: estrutura editorial e elementos básicos. Informação \& Sociedade: Estudos, 25(2), 117-138.

Rosenberg, A. (2008). Biology. In: S. Psillos, \& M. Curd. (Eds.). The Routledge companion to philosophy of science (pp. 511-519). London: Routledge.

Sandoval, W. A. (2005). Understanding student's practical epistemologies and their influence on learning through inquiry. Science Education, 89(4), 634-656.

Schwartz, R. S., Lederman, N. G., \& Lederman, J. S. (2008). An Instrument to Assess Views of Scientific Inquiry: The VOSI Questionnaire. Paper presented at The annual meeting of the National Association for Research in Science Teaching, Baltimore, MD. 
Schwartz, R. S., Lederman, N. G., \& Abd-El-Khalick, F. (2012). A series of misrepresentations: A response to Allchin's whole approach to assessing nature of science understandings. Science Education, 96(4), 685-692.

Shader-Frechette, K., \& McCoy, E. D. (1994). Applied ecology and the logic of case studies. Philosophy of Science, 61(2), 228-249.

Shader-Frechette, K., \& McCoy, E. D. (1993). Method in ecology: strategies for conservation. Cambridge: Cambridge University Press.

Smith, M. U., \& Scharmann, L. C. (1999). Defining versus describing the nature of science: A pragmatic analysis for classroom teachers and science educators. Science Education, 83(4), 493-509.

Stanley, W. B., Brickhouse, N. W. (2001). Teaching science: The multicultural question revisited. Science Education, 85(1), 35-49.

Taber, K. (2010). A comprehensive vision of 'the nature of science" in science education. Studies in Science Education, 46(2), 245-254.

Tsai, C. C., \& Liu, S. Y. (2005). Developing a multidimensional instrument for assessing students' epistemological views toward science. International Journal of Science Education, 27(13), 1621-1638.

Tsai, C., \& Wen, L. (2005). Research and trends in science education from 1998 to 2002: a content analysis of publication in selected journals. Internacional Journal of Science in Education, 27(1), 3-14.

Tucker-Raymond, E., Varelas, M., Pappas, C. C., Korzh, A., \& Wentland, A. (2007). "They probably aren't named Rachel": Young children's scientist identities as emergent multimodal narratives. Cultural Studies of Science Education, 1(3), 559-592.

Waters-Adams, S., \& Nias, J. (2003). Using action research as a methodological tool: Understanding teachers' understanding of science. Educational Action Research, 11(2), 283-300.

Wong, S. L., \& Hodson, D. (2009). From the horse's mouth: What scientists say about scientific investigation and scientific knowledge. Science Education, 93(1), 109-130. 
Nathália Helena Azevedo

[1] http://orcid.org/0000-0003-2075-9121

Universidade de São Paulo

Programa de Pós-Graduação Interunidades em Ensino de Ciências São Paulo, Brasil helena.nathalia@usp.br

Daniela Lopes Scarpa

(1) http://orcid.org/0000-0002-7720-7611

Universidade de São Paulo

Instituto de Biociências

Departamento de Ecologia

São Paulo, Brasil

dlscarpa@usp.br

Submetido em 21 de Outubro 2016

Aceito em 13 de Junho 2017

Publicado em 31 de Agosto de 2017 


\section{Apêndice}

Relação dos periódicos consultados durante a revisão sistemática. Essa listagem originou-se da lista WebQualis 2013 e os periódicos pertencem aos estratos do intervalo A1 a B3, em pelo menos uma das áreas de Educação e Ensino.

\begin{tabular}{|c|c|c|c|}
\hline \multirow{2}{*}{ ISSN } & \multirow{2}{*}{ Título do Periódico } & \multicolumn{2}{|c|}{ Qualis } \\
\hline & & Educação & Ensino \\
\hline $1983-6430$ & A Física na Escola (Online) & B4 & B2 \\
\hline $1517-4492$ & Acta Scientiae (ULBRA) & $\mathrm{B} 2$ & B1 \\
\hline $2178-5198$ & Acta Scientiarum. Education (Print) & A2 & - \\
\hline $1409-4703$ & Actualidades Investigativas en Educación & B3 & - \\
\hline $0342-7633$ & Adult Education and Development & B1 & - \\
\hline $2165-9486$ & Advances in education & - & B2 \\
\hline $1516-1498$ & Ágora (PPGTP/UFRJ) & A2 & - \\
\hline $1133-9837$ & $\begin{array}{l}\text { Alambique - Didactica de las Ciencias Experimentales } \\
\text { (Barcelona) }\end{array}$ & B3 & B1 \\
\hline $1982-5153$ & Alexandria (UFSC) & B3 & B1 \\
\hline $2317-5125$ & $\begin{array}{l}\text { Amazônia - Revista de Educação em Ciências e } \\
\text { Matemáticas (Online) }\end{array}$ & - & B2 \\
\hline 0002-9505 & American Journal of Physics & - & A1 \\
\hline $1678-2690$ & Anais da Academia Brasileira de Ciências (Online) & - & $\mathrm{A} 2$ \\
\hline 2238-3905 & Aprendizagem Significativa em Revista & $\mathrm{C}$ & $\mathrm{B} 2$ \\
\hline $1809-0354$ & Atos de Pesquisa em Educação (FURB) & $\mathrm{B} 2$ & $\mathrm{~B} 1$ \\
\hline 0214-3402 & Aula (Salamanca) & - & $\mathrm{B} 1$ \\
\hline 1414-4077 & Avaliação (UNICAMP) & A1 & $\mathrm{A} 2$ \\
\hline $1470-8175$ & Biochemistry and Molecular Biology Education & - & A1 \\
\hline 2027-1034 & Bio-grafía: escritos sobre la biología y su enseñanza & $\mathrm{C}$ & $\mathrm{B} 1$ \\
\hline 0392-8942 & C n S. La Chimica nella Scuola & - & B3 \\
\hline $2175-7941$ & Caderno Brasileiro de Ensino de Física (Online) & B1 & $\mathrm{B} 1$ \\
\hline $1809-1466$ & Caderno de Física da UEFS & - & B3 \\
\hline 1518-109X & Caderno de Pedagogia (Ribeirão Preto) & B3 & - \\
\hline 0101-3262 & Cadernos CEDES (Impresso) & $\mathrm{A} 2$ & $\mathrm{~A} 2$ \\
\hline 0104-1371 & Cadernos de Educação (UFPel) & A2 & $\mathrm{B} 1$ \\
\hline $0100-1574$ & $\begin{array}{l}\text { Cadernos de Pesquisa (Fundação Carlos Chagas. } \\
\text { Impresso) }\end{array}$ & $\mathrm{A} 1$ & B1 \\
\hline $1519-4507$ & Cadernos de Pesquisa em Educação PPGE-UFES & $\mathrm{B} 4$ & $\mathrm{~B} 2$ \\
\hline $1536-7509$ & Cell Biology Education (Life Sciences Education) & - & A1 \\
\hline $1344-7963$ & Chemical Education Journal & - & A1 \\
\hline $1414-5111$ & Ciência \& Ensino (UNICAMP. Impresso) & B2 & $\mathrm{B} 1$ \\
\hline 0009-6725 & Ciência e Cultura & B1 & $\mathrm{B} 2$ \\
\hline $1516-7313$ & Ciência e Educação (UNESP. Impresso) & $\mathrm{A} 1$ & $\mathrm{~A} 1$ \\
\hline
\end{tabular}




\begin{tabular}{|c|c|c|c|}
\hline \multirow{2}{*}{ ISSN } & \multirow{2}{*}{ Título do Periódico } & \multicolumn{2}{|c|}{ Qualis } \\
\hline & & Educação & Ensino \\
\hline $1806-5821$ & Ciências \& Cognição (UFRJ) & B2 & B2 \\
\hline 0102-8758 & Contexto \& Educação & B3 & $\mathrm{B} 1$ \\
\hline $1668-0030$ & CTS. Ciencia, Tecnología y Sociedad & B2 & - \\
\hline $1871-1502$ & Cultural Studies of Science Education (Print) & A2 & A1 \\
\hline $1645-1384$ & Currículo sem Fronteiras & A2 & $\mathrm{B} 1$ \\
\hline $0362-6784$ & Curriculum Inquiry & A1 & - \\
\hline $2179-6955$ & Debates em Educação Científica e Tecnológica & $\mathrm{C}$ & B2 \\
\hline $1982-2197$ & Diálogos \& Ciência (FTC Feira de Santana. Impresso) & B4 & B3 \\
\hline 0101-465X & Educação (PUCRS. Impresso) & A2 & B3 \\
\hline 1981-8106 & Educação (Rio Claro. Online) & B2 & B3 \\
\hline 0101-9031 & Educação (UFSM) & B1 & B2 \\
\hline $1807-2194$ & Educação e Cultura Contemporânea & B1 & B2 \\
\hline $1982-6273$ & Educação e Fronteiras (UFGD) & B3 & - \\
\hline $1517-9702$ & Educação e Pesquisa (USP. Impresso) & A1 & B1 \\
\hline 0100-3143 & Educação e Realidade & $\mathrm{A} 1$ & B1 \\
\hline $1519-3322$ & Educação em Foco (Belo Horizonte. 1996) & B1 & B2 \\
\hline 0104-3293 & Educação em Foco (Juiz de Fora) & $\mathrm{B} 1$ & $\mathrm{~B} 2$ \\
\hline $2178-8359$ & Educacao em Perspectiva (Online) & B2 & - \\
\hline 0102-4698 & Educação em Revista (UFMG. Impresso) & $\mathrm{A} 1$ & $\mathrm{~A} 2$ \\
\hline $1646-933 X$ & Educacao, Formacao \& Tecnologias & B3 & - \\
\hline 0872-7643 & Educação, Sociedade \& Culturas & $\mathrm{B} 1$ & - \\
\hline $1019-9403$ & Educación (Lima. 1992) & B3 & - \\
\hline 0187-893X & Educación Química & B1 & B1 \\
\hline $1139-613 X$ & Educación XX1 & B1 & - \\
\hline 0123-1294 & Educacion y Educadores & B2 & - \\
\hline $1576-5199$ & $\begin{array}{l}\text { Educacion y Futuro: revista de investigacion aplicada y } \\
\text { experiencias educativas }\end{array}$ & $\mathrm{C}$ & B1 \\
\hline 0104-4060 & Educar em Revista (Impresso) & A1 & $\mathrm{A} 2$ \\
\hline 0300-4279 & $\begin{array}{l}\text { Education 3-13: international Journal of primary, } \\
\text { elementary and early years education }\end{array}$ & B1 & - \\
\hline $1462-7272$ & Education Review (London) & A2 & - \\
\hline 0965-0792 & Educational Action Research & A1 & - \\
\hline $1983-7771$ & Educativa (Goiânia. Online) & B2 & B3 \\
\hline $1316-4910$ & Educere - Revista Venezolana de Educación (Mérida) & $\mathrm{B} 1$ & $\mathrm{~A} 2$ \\
\hline 0104-1037 & Em Aberto & B1 & B3 \\
\hline 0104-4036 & Ensaio (Fundação Cesgranrio. Impresso) & A1 & B4 \\
\hline $1983-2117$ & Ensaio: Pesquisa em Educação em Ciências (Online) & A2 & $\mathrm{A} 2$ \\
\hline $0212-4521$ & Enseñanza de las Ciencias & A1 & $\mathrm{A} 1$ \\
\hline
\end{tabular}




\begin{tabular}{|c|c|c|c|}
\hline \multirow{2}{*}{ ISSN } & \multirow{2}{*}{ Título do Periódico } & \multicolumn{2}{|c|}{ Qualis } \\
\hline & & Educação & Ensino \\
\hline $2237-4450$ & Ensino de Ciências e Tecnologia em Revista & - & B2 \\
\hline 0104-3757 & Ensino em Re-vista (UFU. Impresso) & B3 & B4 \\
\hline $1350-4622$ & Environmental Education Research & - & A1 \\
\hline 0103-6831 & Estudos em Avaliação Educacional (Impresso) & $\mathrm{A} 2$ & B3 \\
\hline 1350-293X & European Early Childhood Education Research Journal & $\mathrm{B} 1$ & - \\
\hline $1474-9041$ & European Educational Research Journal & A1 & - \\
\hline $2000-7426$ & $\begin{array}{l}\text { European Journal for Research on the Education and } \\
\text { Learning of Adults }\end{array}$ & B1 & - \\
\hline $2279-7505$ & European Journal of Research on Education and Teaching & B2 & - \\
\hline $1982-2413$ & Experiências em Ensino de Ciências (UFRGS) & $\mathrm{B} 2$ & B1 \\
\hline $2178-6224$ & Filosofia e História da Biologia (Online) & $\mathrm{B} 2$ & B3 \\
\hline $2176-4360$ & Formação Docente & B3 & - \\
\hline $1130-8656$ & Innovación Educativa & A1 & - \\
\hline 1984-5499 & Instrumento - Revista em estudo e pesquisa em educação & B4 & B3 \\
\hline 0378-1844 & Interciencia (Caracas) & - & A1 \\
\hline $1552-2237$ & $\begin{array}{l}\text { Interdisciplinary Journal of Knowledge and Learning } \\
\text { Objects }\end{array}$ & A2 & - \\
\hline $1807-5762$ & Interface (Botucatu. Online) & A2 & $\mathrm{A} 2$ \\
\hline $2177-7691$ & Interfaces da Educação & $\mathrm{B} 4$ & $\mathrm{~B} 1$ \\
\hline $1913-9020$ & International Education Studies & B1 & - \\
\hline 0883-0355 & International Journal of Educational Research & A1 & - \\
\hline 1571-0068 & $\begin{array}{l}\text { International Journal of Science and Mathematical } \\
\text { Education }\end{array}$ & A1 & - \\
\hline 0950-0693 & International Journal of Science Education & A1 & A1 \\
\hline $1309-6249$ & $\begin{array}{l}\text { International Journal on New Trends in Education and } \\
\text { Their Implications }\end{array}$ & B2 & - \\
\hline 0020-8566 & International Review of Education & A1 & - \\
\hline $1728-5852$ & Investigación Educativa & B3 & - \\
\hline $1518-9384$ & Investigações em Ensino de Ciências (UFRGS. Impresso) & $\mathrm{A} 2$ & $\mathrm{~A} 2$ \\
\hline 1057-896X & JCT (Rochester. New York) & $\mathrm{A} 2$ & - \\
\hline $1029-5968$ & Journal of the International Society for Teacher Education & B1 & - \\
\hline $1740-2743$ & Journal for Critical Education Policy Studies & A2 & A1 \\
\hline $1648-3898$ & Journal of Baltic Science Education & A2 & $\mathrm{B} 1$ \\
\hline 0021-9266 & Journal of Biological Education & $\mathrm{A} 2$ & A1 \\
\hline 0021-9584 & Journal of Chemical Education & - & A1 \\
\hline 0022-0272 & Journal of Curriculum Studies (Print) & A1 & - \\
\hline 0268-0939 & Journal of Education Policy & A1 & - \\
\hline $0022-4308$ & Journal of Research in Science Teaching (Print) & A1 & - \\
\hline $1059-0145$ & Journal of Science Education and Technology & A1 & - \\
\hline
\end{tabular}




\begin{tabular}{|c|c|c|c|}
\hline \multirow{2}{*}{ ISSN } & \multirow{2}{*}{ Título do Periódico } & \multicolumn{2}{|c|}{ Qualis } \\
\hline & & Educação & Ensino \\
\hline $1870-9095$ & Latin - American Journal of Physics Education & - & B1 \\
\hline $2014-2862$ & Multidisciplinary Journal of Educational Research & B1 & - \\
\hline $1648-939 X$ & Natural Science Education & $\mathrm{A} 1$ & B2 \\
\hline 0035-9149 & Notes and Records of the Royal Society of London & - & $\mathrm{A} 2$ \\
\hline $1413-9855$ & Nuances (UNESP Presidente Prudente) & B4 & B1 \\
\hline 0103-863X & Paidéia (USP. Ribeirao Preto. Impresso) & B1 & B2 \\
\hline $1806-0374$ & Periódico Tchê Química (Impresso) & - & B3 \\
\hline 0102-5473 & Perspectiva (UFSC) & $\mathrm{A} 2$ & $\mathrm{~B} 1$ \\
\hline $0210-2331$ & Perspectiva Escolar & - & B3 \\
\hline $2177-1626$ & Pesquiseduca & B2 & B2 \\
\hline 0031-9120 & Physics Education (Bristol. Print) & A1 & A1 \\
\hline $2179-2534$ & $\begin{array}{l}\text { POIÉSIS - Revista do Programa de Pós-Graduação em } \\
\text { Educação (Unisul) }\end{array}$ & B3 & B3 \\
\hline $2178-4442$ & Poiesis Pedagogica & B3 & B2 \\
\hline $1478-2103$ & Policy Futures in Education (Online) & $\mathrm{A} 1$ & - \\
\hline 0717-473X & Praxis & B5 & B3 \\
\hline $1809-4309$ & Práxis Educativa (UEPG. Online) & $\mathrm{A} 2$ & B1 \\
\hline $1822-7864$ & Problems of Education in the Twenty First Century & $\mathrm{B} 2$ & B1 \\
\hline $1980-6248$ & Pró-Posições (UNICAMP. Online) & $\mathrm{A} 1$ & B1 \\
\hline 0327-4829 & Propuesta Educativa (Buenos Aires) & B1 & - \\
\hline 0963-6625 & Public Understanding of Science (Print) & - & $\mathrm{A} 1$ \\
\hline $2177-5796$ & Quaestio: Revista de Estudos de Educação & $\mathrm{B} 2$ & - \\
\hline $1077-8004$ & Qualitative Inquiry & $\mathrm{A} 1$ & - \\
\hline $1353-8322$ & Quality in Higher Education & $\mathrm{A} 1$ & - \\
\hline $1806-8405$ & RBPG. Revista Brasileira de Pós-Graduação & B3 & B1 \\
\hline $1677-3098$ & RECE: Revista Eletrônica de Ciências da Educação & B5 & B3 \\
\hline $1760-7760$ & Recherches \& Éducations & $\mathrm{A} 2$ & - \\
\hline 1954-3077 & Recherches en Éducation & B1 & - \\
\hline $1579-1513$ & REEC. Revista Electrónica de Enseñanza de las Ciencias & $\mathrm{A} 2$ & $\mathrm{~A} 2$ \\
\hline 0103-8842 & Reflexão e Ação (UNISC. Impr.) & B2 & B1 \\
\hline $1679-1916$ & RENOTE. Revista Novas Tecnologias na Educação & B4 & $\mathrm{B} 1$ \\
\hline 1941-3432 & Research in Higher Education Journal & $\mathrm{B} 2$ & - \\
\hline 0263-5143 & Research in Science \& Technological Education & - & $\mathrm{A} 1$ \\
\hline 0157-244X & Research in Science Education & $\mathrm{A} 1$ & $\mathrm{~A} 1$ \\
\hline 1982-131X & Retratos da Escola & $\mathrm{B} 2$ & - \\
\hline $1514-2566$ & Revista Aula Universitaria & - & B3 \\
\hline 1809-449X & Revista Brasileira de Educação & $\mathrm{A} 1$ & - \\
\hline
\end{tabular}




\begin{tabular}{|c|c|c|c|}
\hline \multirow{2}{*}{ ISSN } & \multirow{2}{*}{ Título do Periódico } & \multicolumn{2}{|c|}{ Qualis } \\
\hline & & Educação & Ensino \\
\hline $1677-2318$ & $\begin{array}{l}\text { Revista Brasileira de Ensino de Bioquímica e Biologia } \\
\text { Molecular }\end{array}$ & - & B1 \\
\hline 1982-873X & Revista Brasileira de Ensino de Ciência e Tecnologia & B3 & B1 \\
\hline $1806-9126$ & Revista Brasileira de Ensino de Física (Online) & B2 & A1 \\
\hline $1809-6158$ & Revista Brasileira de Ensino de Química & B3 & B1 \\
\hline 1944-1951 & revista brasileira de estudos pedagógicos & B2 & - \\
\hline $2176-6681$ & Revista Brasileira de Estudos Pedagógicos RBEP-INEP & B1 & - \\
\hline $1806-5104$ & Revista Brasileira de Pesquisa em Educação em Ciências & A2 & A2 \\
\hline 0717-9618 & Revista Chilena de Educación Científica & B2 & B1 \\
\hline $1981-9269$ & Revista Cocar (UEPA) & B2 & B5 \\
\hline 2179-1309 & Revista Contexto \& Educação & B5 & B2 \\
\hline $1516-2907$ & Revista da FACED (Impresso) & $\mathrm{B} 2$ & B4 \\
\hline $1518-7039$ & Revista de Ciências da Educação & B3 & B1 \\
\hline $1678-5622$ & Revista de Educação Popular (Impresso) & B4 & B2 \\
\hline 0104-5962 & Revista de Educação Publica (UFMT) & A2 & B1 \\
\hline $1519-3993$ & Revista de Educação (PUC-Campinas) & B2 & B2 \\
\hline $2238-2380$ & Revista de Educação, Ciências e Matemática & $\mathrm{C}$ & B2 \\
\hline 0124-5481 & Revista de Educacion de las Ciencias & $\mathrm{A} 2$ & A1 \\
\hline 0329-5192 & Revista de Educación en Biología & A2 & B1 \\
\hline 0326-7091 & Revista de Enseñanza de la Física & B1 & B1 \\
\hline 1982-1867 & $\begin{array}{l}\text { Revista de Ensino de Biologia da Associação Brasileira de } \\
\text { Ensino de Biologia (SBEnBio) }\end{array}$ & B3 & B2 \\
\hline 2179-426X & Revista de Ensino de Ciências e Matemática (REnCiMa) & $\mathrm{C}$ & B2 \\
\hline $0102-6437$ & Revista de Estudos Universitárias (Sorocaba) & B2 & B5 \\
\hline 1981-416X & Revista Diálogo Educacional (PUCPR) & $\mathrm{A} 2$ & B1 \\
\hline $1518-1839$ & Revista do Professor (Rio Pardo) & - & B3 \\
\hline $1980-6469$ & Revista Educação (Guarulhos) & $\mathrm{C}$ & B1 \\
\hline $1981-2582$ & Revista Educação (PUCRS. Online) & $\mathrm{A} 2$ & B3 \\
\hline $0102-7735$ & Revista Educação em Questão (UFRN. Impresso) & $\mathrm{A} 2$ & B1 \\
\hline $2316-8919$ & Revista Educação em Rede: formação e prática docente & - & B2 \\
\hline $2237-1648$ & Revista Educação, Cultura e Sociedade & $\mathrm{C}$ & B3 \\
\hline 0121-7593 & Revista Educacion y Pedagogía & B4 & B2 \\
\hline $1607-4041$ & Revista Electrónica de Investigación Educativa & A2 & A1 \\
\hline $1850-6666$ & $\begin{array}{l}\text { Revista Electrónica de Investigación en Educación en } \\
\text { Ciencias }\end{array}$ & B2 & $\mathrm{A} 2$ \\
\hline $2215-8227$ & $\begin{array}{l}\text { Revista eletrônica da associação colombiana para a } \\
\text { pesquisa na educação em ciencias e tecnologias }\end{array}$ & - & B3 \\
\hline 1982-7199 & Revista Eletrônica de Educação (São Carlos) & B2 & B1 \\
\hline
\end{tabular}




\begin{tabular}{|c|c|c|c|}
\hline \multirow{2}{*}{ ISSN } & \multirow{2}{*}{ Título do Periódico } & \multicolumn{2}{|c|}{ Qualis } \\
\hline & & Educação & Ensino \\
\hline $2236-2150$ & $\begin{array}{l}\text { Revista Eletrônica Debates em Educação Científica e } \\
\text { Tecnológica }\end{array}$ & $\mathrm{C}$ & B2 \\
\hline 1697-011X & $\begin{array}{l}\text { Revista Eureka sobre Enseñanza y Divulgación de las } \\
\text { Ciencias }\end{array}$ & B4 & B1 \\
\hline $2236-2983$ & Revista Exitus & $\mathrm{C}$ & B3 \\
\hline $1681-5653$ & Revista Iberoamericana de Educación (Online) & B1 & B1 \\
\hline $1982-5587$ & Revista Ibero-Americana de Estudos em Educação & B1 & - \\
\hline $1695-288 X$ & Revista Latinoamericana de Tecnología Educativa & $\mathrm{A} 2$ & $\mathrm{~A} 2$ \\
\hline $1645-7250$ & Revista Lusófona de Educação & A1 & - \\
\hline $1405-6666$ & Revista Mexicana de Investigación Educativa & $\mathrm{A} 2$ & $\mathrm{~A} 2$ \\
\hline $1665-7527$ & Revista Mexicana de Orientación Educativa & B2 & - \\
\hline 1983-3946 & Revista Pesquisa em Foco em Educação e Filosofia & B4 & B2 \\
\hline 0926-7220 & Science \& Education (Dordrecht) & A1 & A1 \\
\hline 0036-8326 & Science Education (Salem, Mass. Print) & A1 & - \\
\hline $2077-2327$ & Science Education International (Online) & A1 & B1 \\
\hline 0269-8897 & Science in Context & - & $\mathrm{A} 2$ \\
\hline $1818-0361$ & Science in School & - & $\mathrm{B} 1$ \\
\hline 0786-3012 & Science Studies (Tampere) & A1 & - \\
\hline 0971-7218 & Science, Technology and Society & B2 & A2 \\
\hline $1678-3166$ & Scientiae Studia (USP) & B1 & B1 \\
\hline 0039-3746 & Studies in Philosophy and Education & $\mathrm{A} 2$ & - \\
\hline 0305-7267 & Studies in Science Education & A1 & - \\
\hline 2035-844X & Studium Educationis & B2 & - \\
\hline 0742-051X & Teaching and Teacher Education & A1 & - \\
\hline $0102-5503$ & Tecnologia Educacional & B2 & $\mathrm{B} 1$ \\
\hline 1415-837X & Teoria e Prática da Educação & B2 & B4 \\
\hline $1809-1636$ & Vivências (URI. Erechim) & B5 & B2 \\
\hline $2215-8421$ & Voces y Silencios: Revista Latinoamericana de Educación & $\mathrm{C}$ & B1 \\
\hline
\end{tabular}

